\title{
Development and evaluation of a harmonized whole body physiologically based pharmacokinetic (PBPK) model for flutamide in rats and its extrapolation to humans
}

\author{
Raju Prasad Sharma a,b,c, Vikas Kumar ${ }^{\mathrm{a}, *}$, Marta Schuhmacher ${ }^{\mathrm{a}}$, Alexey Kolodkin ${ }^{\mathrm{b}, \mathrm{c}, \mathrm{d}}$, \\ Hans V. Westerhoff ${ }^{\mathrm{b}, \mathrm{c}, \mathrm{e}, \mathrm{f}, * *}$ \\ ${ }^{a}$ Environmental Engineering Laboratory, Departament d'Enginyeria Quimica, Universitat Rovira i Virgili, Av. Països Catalans 26, 43007, Tarragona, Catalonia, Spain \\ ${ }^{\mathrm{b}}$ Molecular Cell Physiology, VU University Amsterdam, the Netherlands \\ ${ }^{\mathrm{c}}$ Infrastructure for Systems Biology Europe (ISBE), Europe \\ ${ }^{\mathrm{d}}$ Luxembourg Centre for Systems Biomedicine, University of Luxembourg, Luxembourg \\ ${ }^{\mathrm{e}}$ Synthetic Systems Biology and Nuclear Organization, Swammerdam Institute for Life Sciences, University of Amsterdam, the Netherlands \\ ${ }^{\mathrm{f}}$ Manchester Centre for Integrative Systems Biology, UK
}

\section{A R T I C L E I N F O}

\section{Keywords:}

PBPK

Flutamide

Flutamide hydroxide

EDCs

\begin{abstract}
A B S T R A C T
By their definition, inadvertent exposure to endocrine disrupting compounds (EDCs) intervenes with the endocrine signalling system, even at low dose. On the one hand, some EDCs are used as important pharmaceutical drugs that one would not want to dismiss. On the other hand, these pharmaceutical drugs are having off-target effects and increasingly significant exposure to the general population with unwanted health implications. Flutamide, one of the top pharmaceutical products marketed all over the world for the treatment of prostate cancer, is also a pollutant. Its therapeutic action mainly depends on targeting the androgen receptors and inhibiting the androgen action that is essential for growth and survival of prostate tissue. Currently flutamide is of concern with respect to its categorization as an endocrine disruptor.

In this work we have developed a physiologically based pharmacokinetic (PBPK) model of flutamide that could serve as a standard tool for its human risk assessment. First we built the model for rat (where many parameters have been measured). The rat PBPK model was extrapolated to human where the re-parameterization involved human-specific physiology, metabolic kinetics derived from in-vitro studies, and the partition coefficient same as the rat model. We have harmonized the model by integrating different sets of in-vitro, in-vivo and physiological data into a PBPK model. Then the model was used to simulate different exposure scenarios and the results were compared against the observed data. Both uncertainty and sensitivity analysis was done.

Since this new whole-body PBPK model can predict flutamide concentrations not only in plasma but also in various organs, the model may have clinical applications in efficacy and safety assessment of flutamide. The model can also be used for reverse dosimetry in the context of interpreting the available biomonitoring data to estimate the degree to which the population is currently being exposed, and a tool for the pharmaceutical companies to validate the estimated Permitted Daily Exposure (PDE) for flutamide.
\end{abstract}

\section{Introduction}

Flutamide is one of the top pharmaceutical products marketed universally all over the world for the treatment of prostate cancer. Its therapeutic action mainly depends on its metabolite flutamide hydroxide, which is a competitive inhibitor of endogenous androgens for binding to their receptors in prostate (Brogden and Clissold, 1989).
Several rat studies revealed flutamide has off target effects, such as decreased weight of the accessory gland, alteration in sex hormone levels in the male rat, and prolongation of the oestrous cycle in female rats (Shin et al., 2002; Toyoda et al., 2000a). Miyata et al. (2002) have linked flutamide exposure to its endocrine related effects in rats. Patients treated with flutamide at its therapeutic dose are always at a higher risk of liver toxicity (Brahm et al., 2011; Tavakkoli et al., 2011),

\footnotetext{
* Corresponding author. Environmental Engineering Laboratory, Departament d'Enginyeria Química, Universitat Rovira i Virgili, Tarragona, Catalonia, Spain.

** Corresponding author.

E-mail addresses: vikas.kumar@urv.cat (V. Kumar), h.v.westerhoff@uva.nl (H.V. Westerhoff).
} 


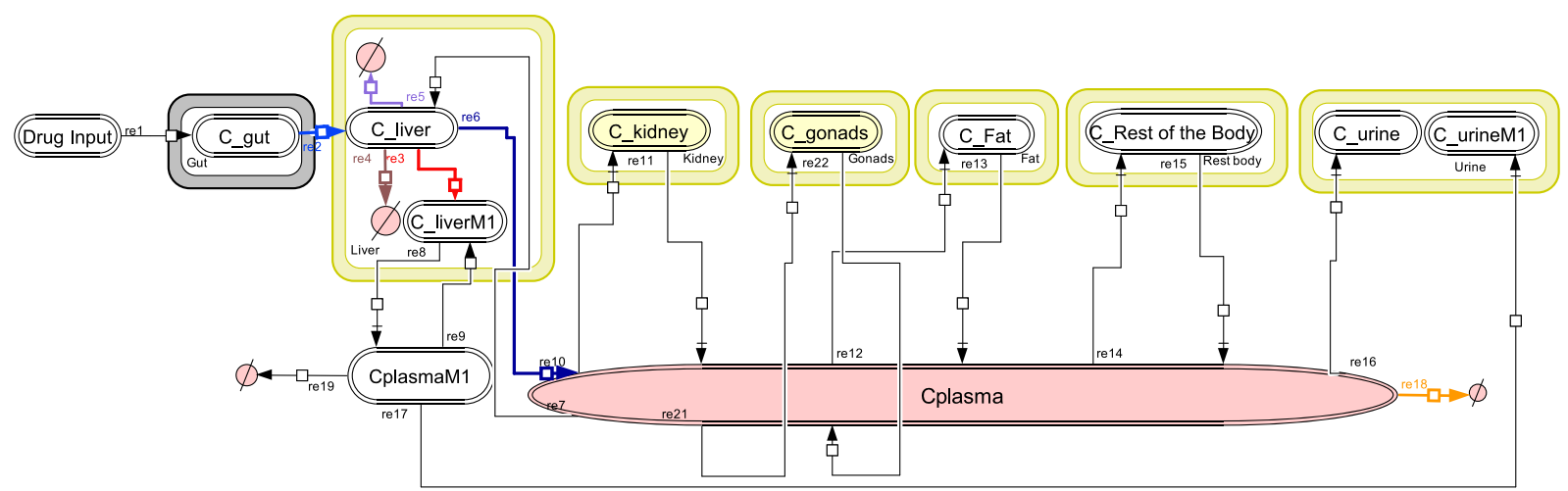

Fig. 1. Minimal PBPK model structure for flutamide and its metabolite flutamide hydroxide. Six tissues, each with a concentration (C) of flutamide (and similarly for flutamide hydroxide) are connected through the blood (plasma). Each compartment has a passive uptake from (as indicated near the beginning of each arrow, reactions re7, re9, re10,re12, re14, re21) and an active release (re6, re8, re11, re22, re13, re15) into the blood, but only the liver can metabolize (reaction re3, re4, re5) and destroy it in its cytosol. re18, re19 corresponds to flutamide and its metabolite flu-OH protein binding. re16, re17 corresponds to urinary excretion of flutamide and its metabolite flu-OH. "M1" corresponds to flutamide hydroxide and "re" corresponds to reactions.

which is presumed to be its idiosyncratic adverse effect. Consequent to an OECD-guideline, repeated-dose, screening for endocrine disruptors compounds (EDCs), flutamide was listed as one of the EDCs (Toyoda et al., 2000b). Endocrine disruptor's chemicals can elucidate toxicity even at low dose (Blumberg et al., 2011). The estimated no observed effect level (NOEL) for flutamide is $0.25 \mathrm{mg} / \mathrm{kg} /$ day (Toyoda et al., 2000b). Mimicking endogenous hormones is considered to be one of the important mechanisms of EDCs.

The current guideline set by European Medicines Agency (EMEA) requires that pharmaceutical companies relate the Permitted Daily Exposure (PDE) (EMEA, 2014) of API (active pharmaceutical ingredients) to their specific toxicological end points. Residuals of active chemicals generated during the manufacturing cycle and exposure to humans via cross contaminated medicinal products should be considered for estimating the PDE (Hayes et al., 2016). Recently flutamide's PDE of $0.025 \mathrm{mg} /$ day was established as safe dose in the context of reproductive and development disorders end points (Zacharia, 2017). Knowing the target tissue concentration and its further integration to the toxicodynamic model should help to predict toxicological endpoints (Sharma et al., 2017a, 2017b).

Upon rapid absorption after oral administration, flutamide undergoes extensive hepatic first-pass metabolism in humans generating several metabolites (Katchen and Buxbaum, 1975). Flutamide metabolites differs between species due to different tissue distribution and different enzyme activities (Kobayashi et al., 2012a, 2012b). Liver CYP1A2 metabolizes flutamide to flutamide hydroxide (Flu-OH) (Radwanski et al., 1989; Shet et al., 1997; Sjo et al., 2009; Sjögren et al., 2014a). Other metabolites include 4-nitro-3-(trifluoromethyl)-aniline (FLU-1) and 2-methyl-N-(4'-amino-3' [trifluoromethyl] phenyl) propanamide (FLU-6) (Kobayashi et al., 2012a, 2012b; Wen et al., 2008). Wen et al. (2008) showed that NADPH: cytochrome P450 reductase (CPR) was involved in producing FLU-6 in liver by nitro reduction of flutamide, which enhances hepatocytes cytotoxicity. Complete elimination of flutamide and its metabolites takes 5 days according to an invivo human study (Katchen and Buxbaum, 1975).

PBPKs models have been applied successfully in toxicology and also welcomed by pharmaceutical companies as an integral tool in drug discovery and development.(Jones et al., 2015; Zhuang and Lu, 2016; Sharma et al., 2018a, 2018b). Not only do they estimate target tissue concentrations, but they also allow interspecies extrapolation, intraspecies dose interpolation, and exposure dose reconstruction. PBPK models are mathematical representations of compartments corresponding to the various physiological organs of the body, linked by the circulating blood system. Each compartment is described by a tissue volume and blood flow rate that is specific to the species of interest. PBPK describes the bio-distribution (absorption, distribution, metabolism and elimination, referred as ADME) and generates time course profiles of chemicals inside the body. A semi-physiologically based biopharmaceutical model has been developed in human for the injectable flutamide hydroxide to estimate the local distribution of the chemical to prostate tissue (Sjögren et al., 2014a). However, to our knowledge there is no full scale PBPK model for flutamide, neither for rats nor for humans.

This article presents physiologically based pharmacokinetic (PBPK) models predicting the time variant concentrations of flutamide in plasma and other organs upon oral dosing in rats and humans. Harmonizing the in-vitro and the animal data using IVIVE and cross species extrapolation methods respectively for the development of whole body PBPK model has shown in this manuscript. The models were used to simulate single and multiple dose scenarios. The simulated data were compared against the data observed in plasma. In the case of the human PBPK, data referring to the flutamide and its metabolite Flu$\mathrm{OH}$ were taken into consideration. Both the bottom up and the top down approach were applied to the development of the model. Prior mean parameter values were obtained either from the published literature or via in-silico or in-vitro and in-vivo experiments, whilst accounting for uncertainties in the range of \pm 1 to \pm 1.5 standard deviations. After a sensitivity analysis, the most uncertain yet influential parameters were distributed statistically for Monte Carlo simulations. We conclude that the models should be suitable for the assessment of flutamide as endocrine disruptor.

\section{Material and methods}

\subsection{PBPK model development}

For both rat and human our PBPK model comprises nine compartments, i.e. gut, liver, plasma, lungs, kidney, fat, gonads, prostate and a compartment representing the rest of the body (Fig. 1). The model is flutamide-specific which includes prostate and gonads; flutamide is used in prostate cancer therapy. The exchange of the flutamide between blood and tissue in each organ is described by flow limited processes i.e. we implemented a perfusion rate-limited PBPK model (not permeability limited). This model works under the assumption that total chemical concentration in the tissue and in the plasma at steady state are in equilibrium with each other. First the model was developed in rats and then extrapolated to humans. Because for the animal models there are more data sets available remaining unmeasurable parameters can be fitted more readily to one group of data sets, whilst using remaining data sets for validation. Accordingly, our strategy was to make an optimal model for rat and then extrapolate this to the human. Oral dosing is considered to be the main route. After an oral exposure, flutamide is 
rapidly absorbed by the system, in a process described using a first order rate constant. Plasma protein binding of flutamide and of its main metabolite (flutamide hydroxide; considered only for human model) was made to conform to the experimentally measured fixed ratio values. The fraction of chemical not bound to plasma proteins is the only fraction of a chemical that is available for transport into organs for metabolism and for clearance.

Distribution parameters such as partition coefficients describe steady state ratios of the concentrations in the plasma and the different organs. Partition coefficients for different organs were derived from the detailed rat in-vivo studies (Asakawa et al. (1995a) using AUC (area under the curve) data. The same partition coefficients were then used for both rat and human PBPK model development. Elimination pathways included both chemical metabolism and its urinary excretion. The metabolism of the flutamide was described using the Michaelis-Menten and Hill equations. Data from literature in-vitro cell line studies for both rat and human were scaled to respective in-vivo using IVIVE approach (in-vitro in-vivo extrapolation) (Howgate et al., 2006a). Validation of the rat model included several in-vivo kinetic data sets for rat resolving 7 compartments, i.e. plasma, liver, lung, kidney, fat, gonads and prostate. For the validation of the human model, kinetic data sets for flutamide and its metabolite flutamide hydroxide in plasma (Radwanski et al., 1989) were used, as well as multiple dose scenario kinetic data sets (Radwanski et al., 1989). Concentrations of the chemical in any compartment were estimated by applying Eq. (1) without metabolism; however metabolic equation, Eq. (3), is included in the respective compartment responsible for metabolism of chemical. A more detailed model description including the equations used for each compartment is available in the Supplementary file.

$\frac{d C i}{d t}=\frac{Q i \times\left(C a-\frac{C i}{K i: p}\right)}{V i}$

where, $C_{\mathrm{i}}$ is the concentration in the tissue $i(\mu \mathrm{g} / \mathrm{L}), \mathrm{Q}_{\mathrm{i}}$ is the blood flow in the tissue $i(\mathrm{~L} / \mathrm{h}), \mathrm{C}_{\mathrm{a}}$ is the arterial concentration $(\mu \mathrm{g} / \mathrm{L}), \mathrm{K}_{\mathrm{i}: \mathrm{p}}$ is the partition coefficient of tissue $i$, and $\mathrm{V}_{\mathrm{i}}$ is the volume of the tissue $i(\mathrm{~L})$. The blood is considered to flow into a well-mixed extracellular compartment in the tissue where the drug is at partition equilibrium with the intracellular drug. Should there be active drug efflux or influx pumping, this is rather a partition steady state where the partition coefficient becomes dependent on the cells' energy state.

\section{2. $P B P K$ model parameterization}

PBPK model parameterization requires physiological parameters, physiochemical properties (fraction unbound and partition coefficient, estimated either by in silico or animal experimentation), and biochemical parameters such as for metabolism (Vmax and Km and other relevant kinetic constants). Our baseline model was for rat and we extrapolated this to the human by adapting the tissue volumes, blood flows through the tissues and the Vmax per unit microsomal protein, and the fraction of microsomal protein per organ on the basis of experimental data. The partition coefficients were considered the same for rat and human.

All the physiological parameters such as blood flow to tissue as a fraction of cardiac blood flow and tissue volume as a fraction of body weight for both rats and human are provided in Table A.1 and A.2 Supplementary Information (SI). Chemical rate constants and metabolic parameters are provided in Table 1 . We have estimated prostate volume and blood flow from the reported literature data, for humans (Inaba, 1992; Sjögren et al., 2014b) and for rats (Shimizu et al., 2015). As per requirement of $\mathrm{PBPK}$, these data were converted into fraction of body weight and fraction of cardiac blood flow, respectively and are provided in Table A.1 and A.2 (SI)). The oral absorption process for the flutamide was described through a first order absorption rate constant $0.62 \mathrm{~h}-1$ (Xu and Li, 1998). The same absorption rate was taken for single and multiple oral doses simulations of the human PBPK model.

We interpreted detailed rat in-vivo data reported in Asakawa et al. (1995a, 1995b) through a method introduced by Gallo et al. (1987) and effectively adapted by others (Lin et al., 2016), This method uses the trapezoidal rule to derive tissue partition coefficients (Kpt) from the AUC (area under the curve) observed in in-vivo animal kinetic profile data of plasma and tissues

$\mathrm{K}_{\mathrm{i}: \mathrm{p}}=\frac{\mathrm{AUC}_{\text {tissue }(0-48)}}{\mathrm{AUC}_{\text {plasma }(0-48)}}$

where, $A U C_{\text {tissue }(0-48)}$ represents the area under the curve for the tissue concentration-time curves from 0 to $48 \mathrm{~h} A U C_{\text {plasma }(0-48)}$ represents the area under the curve for the plasma concentrations-time profile from 0 to $48 \mathrm{~h}$. The values of partition coefficients for different organs used in our rat PBPK model are provided in Table 1.

The average binding percentage of flutamide with plasma protein was reported for rats and human as 60.6 and $91.9 \%$, respectively (Asakawa et al., 1995a). The reported mean value of $95 \%$ for Flu-OH (flutamide hydroxide) for human was used to derive the fraction unbound for Flu-OH, which has also been previously used by Sjögren et al. (2014a) for the development of a semi physiologically based pharmacokinetic model. We assumed that intracellularly the same fraction of flutamide is bound to intracellular proteins. The fractional unbound (fu) for both flutamide and its metabolite flutamide hydroxide are provided in Table 1 .

Flutamide metabolism is described as a saturable process utilizing the Michaelis-Menten equation (Eq. (3)) with parameters Vmax (maximum velocity of metabolic reaction) and $\mathrm{Km}$ (1/affinity, i.e. concentration at which reaction occurs at half maximal rate). The reported in-vitro Vmax values for the tissue microsomal fraction were scaled to in-vivo values using the IVIVE approach (Howgate et al., 2006b), whereas $\mathrm{Km}$ values were kept the same as the in-vitro value. The invitro in-vivo extrapolation (IVIVE) approach utilizes physiological specific parameters such as tissue specific microsomal protein content, specific tissue volume and body weight described in Eq. (4) (Yoon et al., 2014).

$\mathrm{v}_{\mathrm{A}_{\mathrm{mets}}}=\frac{\mathrm{Vmax}^{*} \mathrm{C}_{\mathrm{t}} * \mathrm{f}_{\mathrm{u}}}{\mathrm{Km}+\mathrm{C}_{\mathrm{t}}{ } \mathrm{f}_{\mathrm{u}}}$

where, $\mathrm{Ct}$ is the corresponding concentrations in tissue and fu is the fraction unbound.

$\mathrm{v}_{\mathrm{A}_{\text {mets }}}$ is the rate of production of metabolites.

$\operatorname{Vmax}_{\text {invivo }}=\left(\operatorname{Vmax}_{\text {invitro }} * M S P P G T * V_{\text {tissue }}\right) / B W^{.75}$

where, MSPPGT is the microsomal protein per gram tissue; $\mathrm{V}_{\text {tissue }}$ is the volume of tissue; BW is the body weight and its power to ${ }^{.75}$ is to normalize the scaled Vmax for different body weight persons.

The in-vitro data such as Vmax and $\mathrm{Km}$ for flutamide metabolism in rats were taken from Yuki Kobayashi et al. (2012a, 2012b). This study reported on flutamide metabolism in different tissue cell lines. The in vitro measured specific activity (Vmax) for liver, lung and kidney provided in Table 1 were scaled to whole body in order to obtain the invivo specific intrinsic clearance. For the development of the human PBPK model, the biochemical parameters such as Vmax and Km describing metabolism of flutamide into 3 different metabolites (Fig. 2) were taken from in-vitro hepatic cell line studies (Kobayashi et al., 2012a, 2012b; Sjo et al., 2009; Wen et al., 2008); the corresponding values are provided in Table 1 . Eq. (3), basically involves the extrapolation of the specific activity from in-vitro measured to in-vivo whole body, used for the both rat and human using species specific physiological data such as microsomal protein content of tissue, tissue volume and body weight provided in Table A. (1\& 2) (SI). Our human PBPK model involves three metabolic reactions producing three different metabolites. However, only flutamide hydroxide, which is the major metabolite, was distributed to plasma from the liver site using the same partition coefficient to that of the parent compound. Due to lack of 
Table 1

Flutamide chemical and biochemical specific parameter values and its statistical distributions. LN: LOG NORMAL LN (a,b) means a = LN (mean) and $\mathrm{b}=$ standard deviation in LN space.

\begin{tabular}{|c|c|c|c|c|}
\hline Parameters & Symbols & Units & Values or distributions & References \\
\hline \multicolumn{5}{|l|}{ Partition coefficients- } \\
\hline Liver/Plasma & Kpt:liver/plasma & & $L N(5.57,1.5)$ & a \\
\hline Lung/Plasma & Kpt:lung/plasma & & $L N(1.65,1.1)$ & $\mathrm{a}$ \\
\hline Kidney/Plasma & Kpt:kidney/plasma & - & $L N(2.63,1.5)$ & a \\
\hline Fat/Plasma & Kpt:fat/plasma & - & $L N(2.78,1.1)$ & a \\
\hline gonads/Plasma & Kpt:gonads/plasma & - & $L N(1.7,1.5)$ & a \\
\hline prostate/Plasma & Kpt:prostate/plasma & - & $L N(2.17,1.1)$ & $\mathrm{a}$ \\
\hline Rest of the body/Plasma & Kpt:restbody/plasma & - & $L N(5.57,1.1)$ & a \\
\hline Liver/Plasma (FLU-OH) & Kpt:liver/plasmaM1 & - & $L N(5.57,1.5)$ & $\mathrm{a}$ \\
\hline \multicolumn{5}{|l|}{ Absorption and elimination parameters } \\
\hline Unbound fraction in plasma (Flutamide) & $\mathrm{fu}$ & - & 0.09 & Asakawa et al. (1995a) \\
\hline Unbound fraction in plasma (Flu-OH) & fu1 & - & 0.05 & Sjogren et al. (2014a, 2014b) \\
\hline Oral absorption rate & kgut & $1 / \mathrm{h}$ & $\mathrm{LN}(0.64,1.1)$ & $\mathrm{a}$ \\
\hline Elimination rate & kurine & $1 / \mathrm{h}$ & LN $(1.25,1.5)$ & optimized \\
\hline Elimination rate (FLU-OH) & kurineM1 & $1 / \mathrm{h}$ & LN $(1.85,1.5)$ & optimized \\
\hline \multicolumn{5}{|l|}{ Metabolic parameters for human } \\
\hline Flu to Flu-OH maximum reaction value & VmaxlivM1_invitro & $\mu \mathrm{g} / \mathrm{min} / \mathrm{mg}$ MSP & $\mathrm{LN}(0.079,1.1)^{\mathrm{b}}$ & Sjo et al. (2009) \\
\hline Conc. at half maximum value & KmliverM1 & $\mathrm{mg} / \mathrm{L}$ & 1.113 & Sjo et al. (2009) \\
\hline Flu to Flu- 6 maximum reaction value & VmaxlivM2_invitro & $\mu \mathrm{g} / \mathrm{min} / \mathrm{mg}$ MSP & $\mathrm{LN}(0.052,1.1)^{\mathrm{b}}$ & Wen et al. (2008) \\
\hline Conc. at half maximum value & KmliverM2 & $\mathrm{mg} / \mathrm{L}$ & 23.754 & Wen et al. (2008) \\
\hline Flu to Flu-1 maximum reaction value & VmaxlivM3_invitro & $\mu \mathrm{g} / \mathrm{min} / \mathrm{mg} \mathrm{MSP}$ & $\mathrm{LN}(0.31,1.1)^{b}$ & Kobayashi et al. (2012a) \\
\hline Conc. at half maximum value & KmliverM3 & $\mathrm{mg} / \mathrm{L}$ & 82.863 & Kobayashi et al. (2012a) \\
\hline \multicolumn{5}{|l|}{ Metabolic parameters for rat } \\
\hline Unbound fraction in plasma & $\mathrm{fu}$ & - & $\mathrm{LN}(0.4,1.5)$ & Asakawa et al. (1995a) \\
\hline Flu metabolism in liver & VmaxlivM1_inviro & $\mu \mathrm{g} / \mathrm{min} / \mathrm{mg} \mathrm{MSP}$ & $\mathrm{LN}(0.8,1.2)^{\mathrm{b}}$ & Kobayashi et al. (2012a) \\
\hline Conc. at half maximum value & KmliverM1 & $\mathrm{mg} / \mathrm{L}$ & 276 & Kobayashi et al. (2012a) \\
\hline Flu metabolism in kidney & VmaxkidM1_invitro & $\mu \mathrm{g} / \mathrm{min} / \mathrm{mg} \mathrm{MSP}$ & $\mathrm{LN}(0.75,1.1)^{\mathrm{b}}$ & Kobayashi et al. (2012a) \\
\hline Conc. at half maximum value & KmkidneyM1 & $\mathrm{mg} / \mathrm{L}$ & 1600 & Kobayashi et al. (2012a) \\
\hline Flutamide metabolism in lung & VmaxlungM1_invitro & $\mu \mathrm{g} / \mathrm{min} / \mathrm{mg}$ MSP & $\mathrm{LN}(0.028,1.1)^{\mathrm{b}}$ & Kobayashi et al. (2012a) \\
\hline Conc. at half maximum value & KmlungM1 & $\mathrm{mg} / \mathrm{L}$ & 193 & Kobayashi et al. (2012a) \\
\hline Oral absorption rate & kgut & $1 / \mathrm{h}$ & $\mathrm{LN}(0.64,1.1)^{\mathrm{a}}$ & optimized \\
\hline Renal clearance & $\mathrm{Cl}_{\mathrm{R}}$ & $\mathrm{L} / \mathrm{h}$ & $\mathrm{LN}(0.07,1.5)^{\mathrm{c}}$ & optimized \\
\hline
\end{tabular}

a Derived from sources explained in parameterization section 2.2 and using same value in case of both rat and human PBPK model.

b Parameters are scaled to whole body species prior to use in model.

c Rat glomeration filtration rate was considered.

specific data on the generation of different metabolites, no metabolites were included in the current rat PBPK model. However clearance of flutamide is considered in that model, including its metabolism in rat lung, rat liver and rat kidney as reported by Yuki Kobayashi et al. (2012a, 2012b) in in-vitro cell line studies. Elimination rate constants for both flutamide and flutamide hydroxide were visually optimized to fit the plasma data of human studies carried out by (Radwanski et al., 1989). The flutamide elimination rate constant was needed to optimize in order to match the observed data knowing the fact that there are some unknown flutamide catabolism pathways.

\section{CXP1A2}

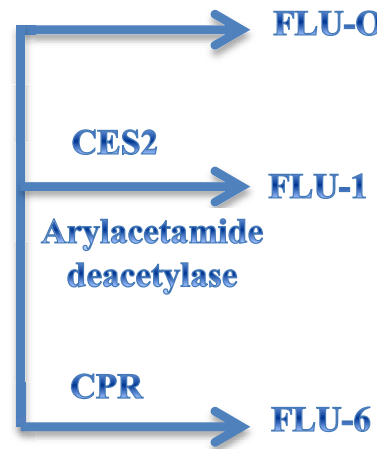

\subsection{Sensitivity analysis}

A sensitivity analysis was carried out both for the rat and for the human PBPK model. The R package FME was used, which measures the alteration in model output for variable of interest by changing each parameter by $1 \%$ change up and down whilst keeping the other ones constant. Detailed information about the functions of FME can be found in Soetaert and Petzoldt (2010).

Sflutamide, $j(t)=\frac{\partial[\text { flutamide }(t)]}{\partial p_{j}} * \frac{p_{j}}{[\text { flutamide }(t)]}=\frac{\partial \ln [\text { flutamide }(t)]}{\partial \ln p_{j}}$

Where, $S$ [flutamide $(t)], j$ is the sensitivity of the flutamide

FLU-OH $=2$ hydroxy flutamide

FLU-1 = 4-nitro-3-(trifluoromethyl)-

aniline

FLU-6 = 2-methyl-N-(4'-amino-3'-

[trifluoromethyl]phenyl)propanamide

CYP1= cytochrome P450 1A2

$\mathrm{CES} 2=$ carboxy esterase

$\mathrm{CPR}=\mathrm{NADPH}$ : cytochrome P450

reductase

Fig. 2. Schema for human flutamide metabolism; Liver CYP1A2 metabolizes flutamide into flutamide hydroxide, main metabolite. Deacetylation of flutamide by carboxylesterase generates Flu-1. Reduction of aromatic nitro group into amino group by cytochrome reductase results in conversion of Flutamide to FLU-6. 
(a)

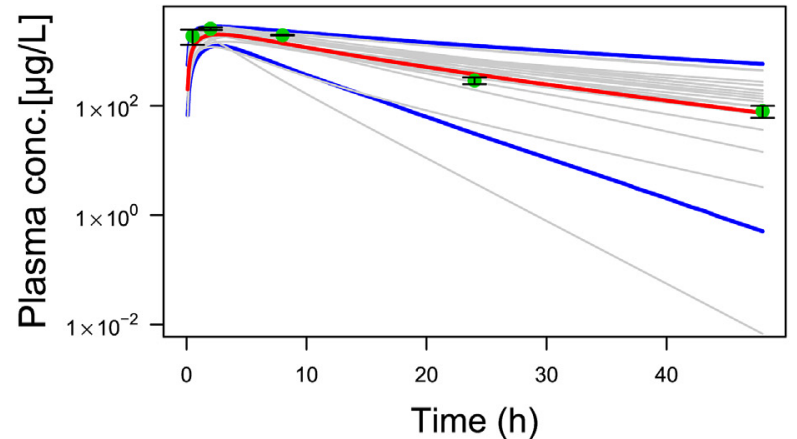

(c)

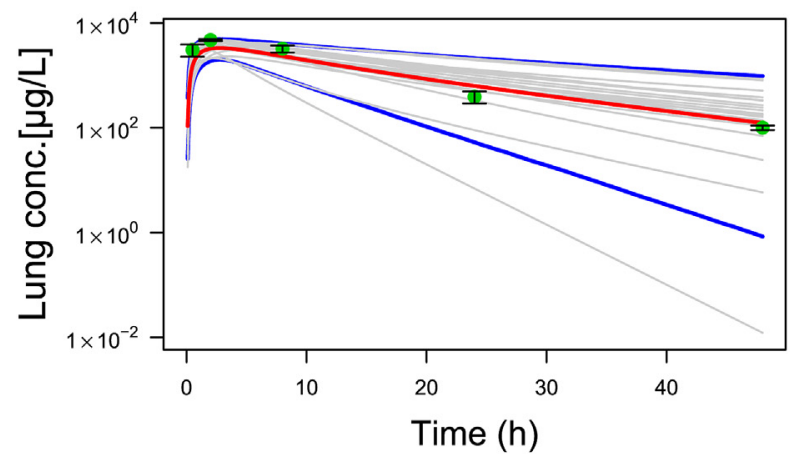

(e)

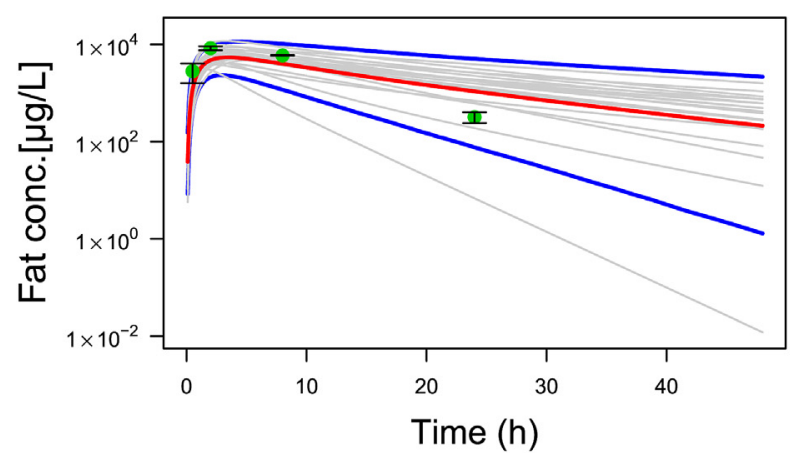

(g)

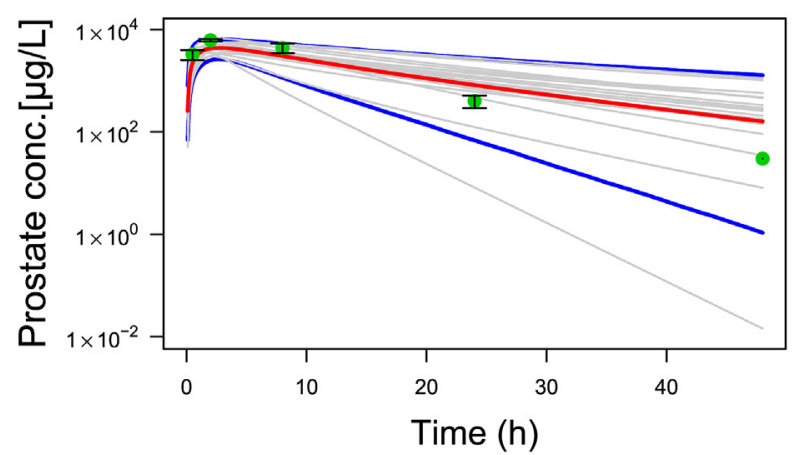

Fig. 3. (a-g): PBPK model predictions of flutamide concentration in various rat compartments following $5 \mathrm{mg} / \mathrm{kg}$ oral dose of flutamide. Blue lines: 2.5 and 97.5 percentiles; Gray lines: 20 simulations chosen at random from the ensemble of 15,000 iterations where the parameters were chosen at random within the confines of their log normal distribution parameterized as provided in Table 1. Red lines: median prediction taken from the ensemble of 15,000 iterations; the green dots indicate the mean concentrations and black lines indicate the mean \pm sd reported in (Asakawa et al. (1995a). For the fat compartment (e), the data for $48 \mathrm{~h}$ was not available. (For interpretation of the references to colour in this figure legend, the reader is referred to the Web version of this article.) (b)

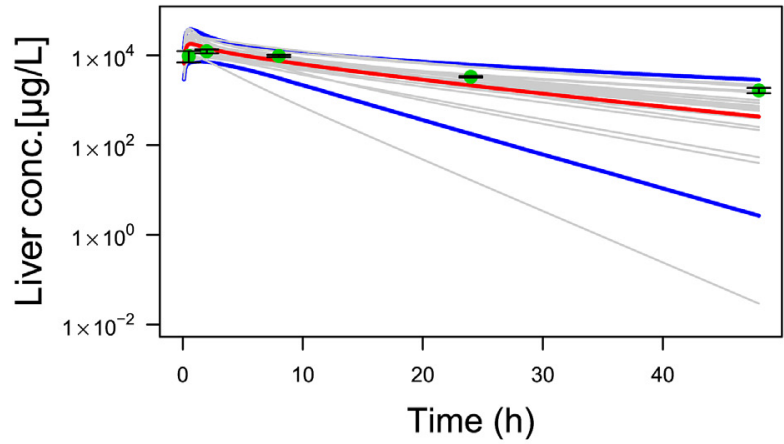

(d)

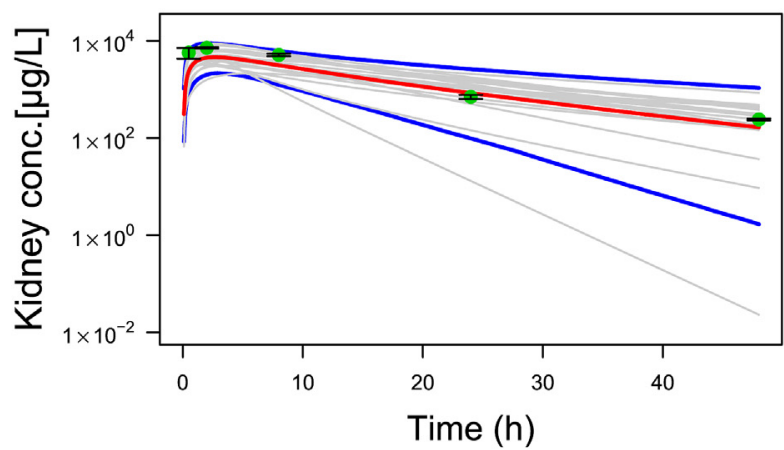

(f)

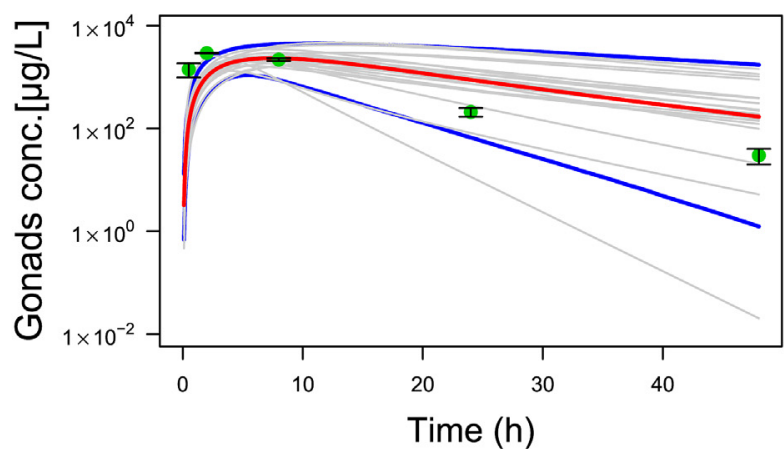


concentration to any time-independent parameter $\mathrm{pj}$, normalized by both the model variable and the parameter value and thereby dimensionless. $p j$ is any parameter of the PBPK model and [flutamide $(t)]$ is the scaling of variable i.e. flutamide plasma concentration.

These sensitivity functions collapsed into a summary of sensitivity values. The magnitude of the time-averaged sensitivity values were used to rank the parameters. This includes the absolute values of the sensitivity coefficients $|S|$ i.e. flutamide $(\mathrm{t})$ - flutamide $(\mathrm{t})(\mathrm{pj})$ termed as least absolute deviation, the average of their squares $S^{2}$ termed as least square error, and their average $S_{\text {mean }}(t)$, their lowest $S_{\text {min }}$ and their highest value $\left(S_{\text {max }}\right)$, where $|S|$ norm $(t)=\sum_{j=1}^{n_{p}} \frac{|S j(t)|}{n_{p}}$ and $S^{2}=\sqrt{\sum \frac{\left(S_{i j}^{2}\right)}{n}}$.

There are two different time average $S$ coefficients: one takes the time average of the coefficients; the other takes the sensitivity of the time average.

The former is:

$\frac{1}{T} \cdot \sum_{t=0}^{t=T} \frac{\partial \ln [\text { flutamide }(t)]}{\partial \ln p_{j}}$

The latter is:

$\frac{\partial \ln \left(\frac{1}{T} \cdot \sum_{t=0}^{t=T}[\text { flutamide }(t)]\right)}{\partial \ln p_{j}}=\frac{\frac{1}{T} \cdot \partial \ln (A U C)}{\partial \ln p_{j}}$

\subsection{Model simulation}

The PBPK model was developed using ordinary differential equations describing the kinetics of flutamide. The equations were written in the GNU MCSim modeling language (Bois and Maszle, 1997) and solved by numerical integration with the GNU MCSim, using the R platform. And a priori information was taken from in vitro and in-vivo experiments reported in the literature. Sensitivity analysis considered mean values of parameters. Monte Carlo (MC) simulations were performed to estimate the impact on model predictions of uncertainty in all of the rate constants, the partition coefficients, and the Vmax of the metabolizing enzyme. MC simulation consisted of 15,000 iterations and each corresponded to simulation of the model equations with parameter set defined by a random sample from the probability distributions provided in Table 1. The observed experimental data were used for model calibration and evaluation. The model was considered to be fit, if all the observed data fell within the range of output simulation between the 2.5th and 97.5th percentile.

\subsection{Calibration and evaluation of PBPK model}

First the calibration and then validation of the model was done using data on several compartments. Most of the data were taken from the in-vitro and in-vivo experiments. The unknown parameters prior values were first calibrated against the observed in-vivo data and the logarithms of their values were then assigned a normal distribution. To validate the rat PBPK model, rat experimental data for different organs were used from the Asakawa et al. (1995a) study involving a single oral administration of flutamide at a dose $5 \mathrm{mg} / \mathrm{kg}$. The mean weight of the rats was $250 \mathrm{~g}$. The time course profile of flutamide concentration in plasma and different organs were recorded at 0.5, 2, 8, 24 and $48 \mathrm{~h}$. The output concentrations data were expressed as the mean $(\mu \mathrm{g} / \mathrm{ml}) \pm \mathrm{SD}$. The units were converted into $\mu \mathrm{g} / \mathrm{L}$ in order to make simulation output and observed data uniform. The kinetic profile for seven compartments, namely plasma, liver, lung, kidney, fat, gonads and prostate were used to evaluate the performance of the model.

An experimental human study by Radwanski et al. (1989) in which volunteers were orally administered $0.25 \mathrm{~g}$ of flutamide was used to evaluate the human PBPK model. The subject characteristics include mean weight, height and age of $89 \mathrm{~kg}, 180 \mathrm{~cm}$ and 66 year, respectively. The study involved two case scenarios: One was administration of a single oral dose of $0.25 \mathrm{~g}$ and then measuring the time course profile of flutamide and its metabolite flutamide hydroxide in plasma at $0,0.5,1,1.5,2,3,4,6 \mathrm{~h}$ and at $0,0.5,1,1.5,2,3,4,6,8,12$, $16,24 \mathrm{~h}$, respectively. The second scenario included multiple dosing, i.e. on the first day a single oral dose of $0.25 \mathrm{~g}$, then a dose of $0.25 \mathrm{~g}$ three times a day from the 2nd to the 8th day. The observed concentration in plasma on the 6th and the 9th day were recorded for both flutamide and flutamide hydroxide. The data are expressed in mean (ng/ml $\sim \mu \mathrm{g} / \mathrm{L}$ ) and SD.

\section{Results}

\subsection{Rat PBPK model}

The rat PBPK model was used to simulate the experimental data obtained by Asakawa et al. (1995a) for seven different compartments after oral administration of $5 \mathrm{mg} / \mathrm{kg}$ to the rat. The model prediction results are presented in Fig. 3(a-g) for 20 random predictions; their median (red), and their two extremes corresponds to 2.5 and 97.5 percentiles (blue). The green points represent the experimentally observed mean concentrations, the black bars represents \pm standard deviation. Overall, the experimental in-vivo time course concentrations for several organs Fig. 3(a-g) were adequately predicted by the model. In most of the compartments, model slightly under-predicted the rate of appearance i.e. initial observed experimental points are at or near the 97.5th of the modeling percentile. This indicates that model prediction uncertainty is still much higher than experimental uncertainty: the model uncertainty exceeds the experimental noise and it should therefore be possible to improve the model further by a more precise determination of its parameters. The under-prediction of initial time points by the model could be due to the under-estimation of the gut absorption rate constant parameter. This fact is further supported by the sensitivity results (Table 2), where the gut absorption rate constant parameter has high positive sensitivity coefficient among all other parameters. However, terminal experimental points are close to the predicted median line.

The results also show that the flutamide concentrations in plasma (Fig. 3a) were lower than in the other compartments. Fig. 4 (a) shows the flutamide concentrations in various organs relative to the concentration in the prostate, again as a function of time. An optimal drug against prostate cancer should have a much lower concentration in gonads and liver, i.e. in organs where this drug is suspected to have side effects other than in prostate, where it is supposed to be active against the tumor. And it should have a much lower concentration in liver, where it is removed by metabolism and where metabolic products may cause idiosyncratic liver damage. None of this is true, neither for the model nor for the experimental results. Endocrine related adverse effects shown by flutamide are thought to be mediated by its action in gonads. Here PBPK model shows that flutamide concentrations in the gonad and also in liver is higher than in the plasma, indicating importance of knowing target concentration and thus risk assessment based on tissue dosimetry model.

Fig. 4 (b) shows the results of AUC as a function of time for plasma, liver, gonads and prostate. After an hour, these organs have had their $90 \%$ integral dose. This suggests that multiple low dose would be advantageous than compare to high dosing once a day. With multiple dosing scenarios, one may able to maintain the therapeutic concentrations at target site with minimal exposure to off target organ such as gonads. In contrast single high dosing of flutamide could increase its non-target organs exposure where drug flushes out slowly (mean residence time is higher).

\subsection{Human PBPK model}

When simulating tissue concentrations for the human model, the 
Table 2

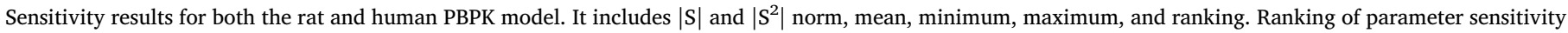
coefficient was done based on $|S|$ that measures least absolute deviation of output (here flutamide plasma concentration).

Response variable: Flutamide Plasma concentrations in rat

(A) Summary statistics of parameters' sensitivities

\begin{tabular}{|c|c|c|c|c|c|c|}
\hline Parameters & $|\mathrm{S}|$ & $\left|S^{2}\right|$ & $\mathrm{S}_{\text {mean }}$ & $\mathrm{S}_{\min }$ & $\mathrm{S}_{\max }$ & Rank \\
\hline kgut & 1.826 & 0.134 & 0.3 & -1.04 & 63.48 & 1 \\
\hline $\mathrm{fu}$ & 1.581 & 0.048 & -1.579 & -3.028 & 0.564 & 2 \\
\hline kurine & 1.076 & 0.033 & -1.076 & -2.199 & 0 & 3 \\
\hline K_kidney_plasma & 1.069 & 0.033 & -1.069 & -2.178 & 0 & 4 \\
\hline K_restbody_plasma & 0.742 & 0.023 & 0.607 & -0.533 & 1.643 & 5 \\
\hline KmliverM1 & 0.736 & 0.02 & 0.736 & 0 & 0.974 & 6 \\
\hline K_liver_plasma & 0.616 & 0.017 & -0.616 & -0.960 & 0 & 7 \\
\hline VmaxliverM1 & 0.409 & 0.011 & -0.409 & -0.542 & 0 & 8 \\
\hline K_fat_plasma & 0.142 & 0.004 & 0.116 & -0.095 & 0.318 & 9 \\
\hline K_gonads_plasma & 0.008 & 0 & 0.006 & -0.004 & 0.023 & 10 \\
\hline K_lung_plasma & 0.007 & 0 & 0.006 & -0.009 & 0.015 & 11 \\
\hline K_prostate_plasma & 0.003 & 0 & 0.002 & -0.006 & 0.005 & 12 \\
\hline KmkidneyM1 & 0.002 & 0 & 0.002 & -0.001 & 0.003 & 13 \\
\hline VmaxkidneyM1 & 0.001 & 0 & -0.001 & -0.008 & 0.004 & 14 \\
\hline KmlungM1 & 0 & 0 & 0 & -0.002 & 0.001 & 15 \\
\hline VmaxlungM1 & 0 & 0 & 0 & 0 & 0 & 16 \\
\hline K_liver_plasmaM1 & 0 & 0 & 0 & 0 & 0 & 17 \\
\hline
\end{tabular}

Response variable: Flutamide Plasma concentrations in human

\begin{tabular}{|c|c|c|c|c|c|c|}
\hline k_liver_plasma & 0.987 & 0.037 & -0.987 & -0.997 & 0 & 1 \\
\hline vmaxliverM1 & 0.95 & 0.035 & -0.95 & -0.992 & 0 & 2 \\
\hline kmliverM1 & 0.904 & 0.034 & 0.904 & 0 & 0.928 & 3 \\
\hline k_restbody_plasma & 0.513 & 0.021 & -0.513 & -0.721 & 0 & 4 \\
\hline kurine & 0.408 & 0.016 & -0.408 & -0.510 & 0 & 5 \\
\hline kgut & 0.348 & 0.020 & -0.239 & -1.126 & 1.006 & 6 \\
\hline fu & 0.294 & 0.014 & -0.065 & -0.837 & 0.798 & 7 \\
\hline vmaxliverM3 & 0.053 & 0.002 & -0.053 & -0.057 & 0 & 8 \\
\hline kmliverM3 & 0.053 & 0.002 & 0.053 & 0 & 0.057 & 9 \\
\hline k_fat_plasma & 0.051 & 0.002 & -0.051 & -0.071 & 0 & 10 \\
\hline vmaxliverM2 & 0.031 & 0.001 & -0.031 & -0.034 & 0 & 11 \\
\hline kmliverM2 & 0.031 & 0.001 & 0.031 & 0 & 0.034 & 12 \\
\hline k_lung_plasma & 0.023 & 0.001 & 0.017 & -0.024 & 0.051 & 13 \\
\hline k_kidney_plasma & 0.01 & 0.001 & 0.006 & -0.048 & 0.032 & 14 \\
\hline k_prostate_plasma & 0.001 & 0 & 0.001 & -0.004 & 0.005 & 15 \\
\hline k_gonads_plasma & 0 & 0 & 0 & -0.00012 & -0.0002 & 16 \\
\hline k_liver_plasmaM1 & 0 & 0 & 0 & 0 & 0 & 17 \\
\hline kurineM1 & 0 & 0 & 0 & 0 & 0 & 17 \\
\hline fu1 & 0 & 0 & 0 & 0 & 0 & 17 \\
\hline
\end{tabular}

partition coefficients parameters were kept the same than for rat model, whereas the rate constant for absorption was estimated by using the reported (Xu and Li, 1998) absorption half-life of 1-2 h. Fig. 5 (A-B) represents the simulated time course of flutamide and its metabolite flutamide hydroxide in plasma following a single oral dose of $0.25 \mathrm{~g}$. Remarkably, for this extrapolation from rat to human, the 2.5-97.5 percentile of the distribution of the modeling results still includes the experimental results. For flutamide itself, the variation in model prediction is now virtually equal to the experimental variability, suggesting that no further model improvement is called for. Here the experimental reproducibility should be enhanced if it is due to experimental error, or, if it is due to biological variability between individual humans, we therefore should move to individualized models. For flutamide hydroxide the model variability is still a wee bit higher than the experimental variability; here some parameters need to be improved.

Fig. 5 (A) shows a small over-prediction by the model of the flutamide concentrations at early times after administration, as compared to the experimental results. At early times, flutamide hydroxide is underpredicted. This suggests that the model underestimates flutamide catabolism to flutamide hydroxide.

The flutamide concentrations decreased within $24 \mathrm{~h}$ to significantly lower levels. Therefore, we also simulated repeated dosing of the drug.
All the parameters were keep the same for multiple dose scenario simulations, which involved 1st day single dose of $0.25 \mathrm{~g}$ and then three times in day from 2nd to 8th day oral dose of $0.25 \mathrm{~g}$ and the results are presented in Fig. 6(A-B). Again, all the observed mean points are within the simulated range shows data agreement between simulated and observed. The increase in concentration of flutamide and flutamide for multiple oral doses was captured by the model which has been also observed in human experimental study.

Further simulation for $48 \mathrm{~h}$ after a single oral dose of $0.25 \mathrm{~g}$ for several compartments keeping all parameters equal is presented in Fig. 7 (A-F). As expected, initially the liver gets a very high concentration of flutamide and then decreases very rapidly as liver actively metabolizes it. Flutamide concentrations into fat and gonads are much lower than in other compartments. Fig. 7 (D \& E) kinetics profile shows that flutamide concentration in these two organs might have longer residence time. This observation should be further investigated, which might be very important as the endocrine effects of flutamide are mainly targeted to the gonads.

\subsection{Parameter sensitivity}

A sensitivity analysis was carried out for all the parameters that were used for the development of the PBPK model. The summarized 
(a)

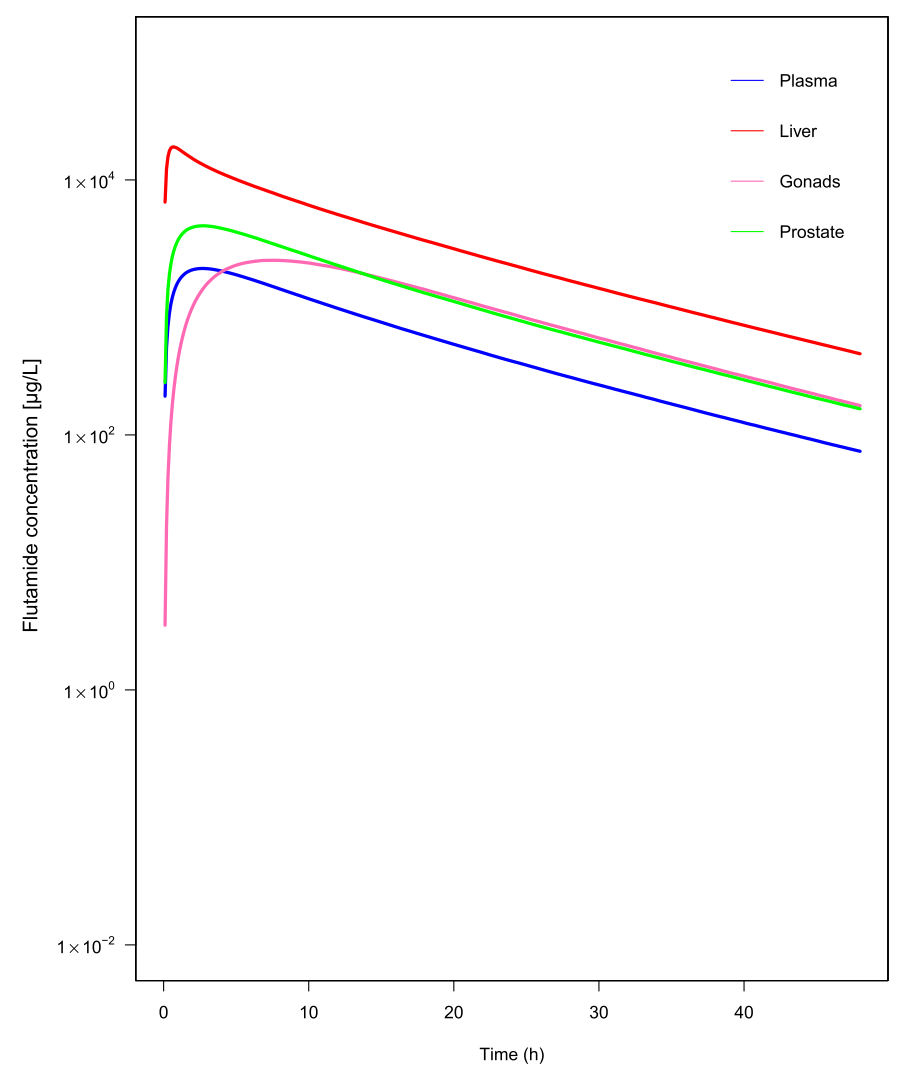

(b)

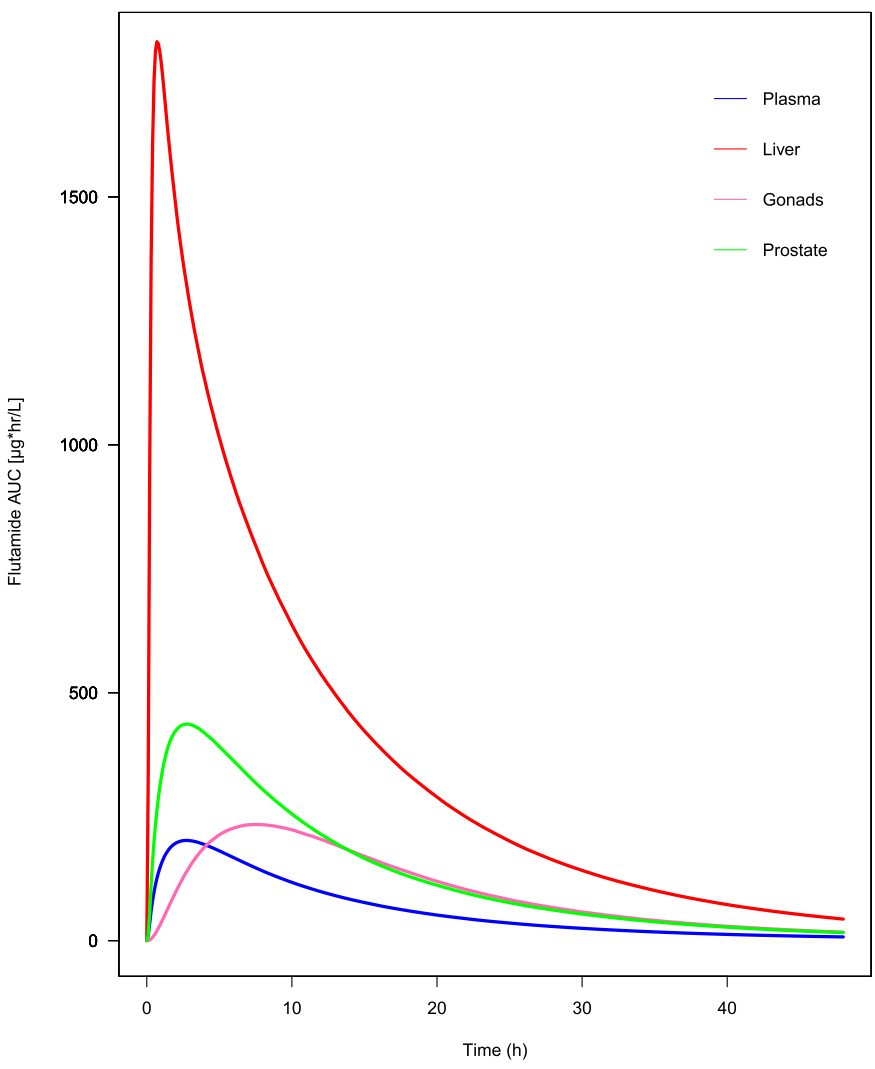

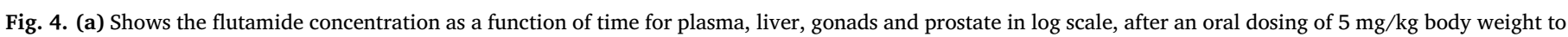
the rats. (b) shows the AUC as a function of time for plasma, liver, gonads and prostate, after an oral dosing of $5 \mathrm{mg} / \mathrm{kg}$ body weight to the rats.

table results for the rat and human PBPK models are provided in Table 2. It includes $|S|$ and $\left|S^{2}\right|$ norm, mean, minimum, maximum, and ranking. The table summarizes the statistics of the normalized and dimensionless parameter sensitivity results. Ranking of parameter sensitivity coefficient was done based on $|\mathrm{S}|$ that measures least absolute deviation of output (here flutamide plasma concentration).

Sensitivity coefficients results for different parameters are provided in Table 2 (A-B). In turn Fig. 8 (A-B) represents the mean sensitivity coefficients. As expected, the sensitivity coefficients of the flutamide concentrations to urine is negative: urine secretes the compound. In humans, the flutamide level in plasma is modelled to be strongly influenced by diuresis: its sensitivity coefficient is -1 , meaning that a $10 \%$ activation of urination should decrease the flutamide level by $10 \%$. Surprisingly, the sensitivity towards the gut activity is much smaller than expected in the rat model and even negative in the human. The latter finding suggests that the activation of flutamide uptake from the gut cause a decrease in the level of flutamide in the plasma. The explanation is that increased liver uptake of the flutamide activates flutamide metabolism earlier; initially the plasma flutamide concentration may be higher, but the drug is removed more quickly from the body by liver detoxification (first pass metabolic effect). Indeed, in the human the plasma flutamide concentration depends strongly on the drug detoxification reaction in liver, at a sensitivity coefficient of around -1 . This shows that flutamide metabolism is an important process for determining the flutamide concentration in plasma. The mean sensitivity coefficient of Vmax is negative and $\mathrm{Km}$ is positive. This result suggests that adding these two parameters have opposite effect on flutamide concentration. Statistical distribution of both parameters simultaneously would result in compensation into the output variable i.e. flutamide plasma concentrations. Thus, we restricted probability distributions to Vmax only for the uncertainty analysis, so that it would not influence the output result.

The expectation that the binding fraction to proteins (fu) has a negative control over the free plasma flutamide concentrations was expected because the binding will lower its free concentration. Likewise one should expect that the partition coefficients exert negative control on the plasma flutamide concentrations. The sensitive coefficient at min and max of partition coefficients for liver, kidney exert negative effect or no effect (zero) on flutamide concentration (Table 2(A)). Indeed, both the liver and the kidney causes clearance of flutamide; in other word, flutamide is not retained in these organs. But for the other tissues such as fat, gonads, lung and prostate, sensitivity coefficient ranges from negative to positive. This indicates that their partition coefficient exert a positive control on the flutamide concentration at the later times. It could be explained by the fact that drug might be retained for longer in these organs, as these are non-metabolizing organs. Accordingly to the results showed in Table 2 (B), the maximum sensitivity coefficient values are in this order: Rest of body $>$ Fat $>$ Lung $>$ Prostate > Gonads.

\section{Discussion}

The present study is the first attempt to develop a two species (Rat and Humans) PBPK model simulating the concentrations of flutamide in various tissues following a single or repetitive oral dose. The model was parameterized on the basis of harmonization of a different set of data such as species-specific physiological data, physicochemical data and independent biochemical data on metabolism such as in-vitro data for both rats and humans. The human model was made specific by inserting human specific data for enzyme activities, organ volumes and blood flow through each organ. Partition coefficients were kept the same as for the rat model. Parameter uncertainties were handled by running 
(A)

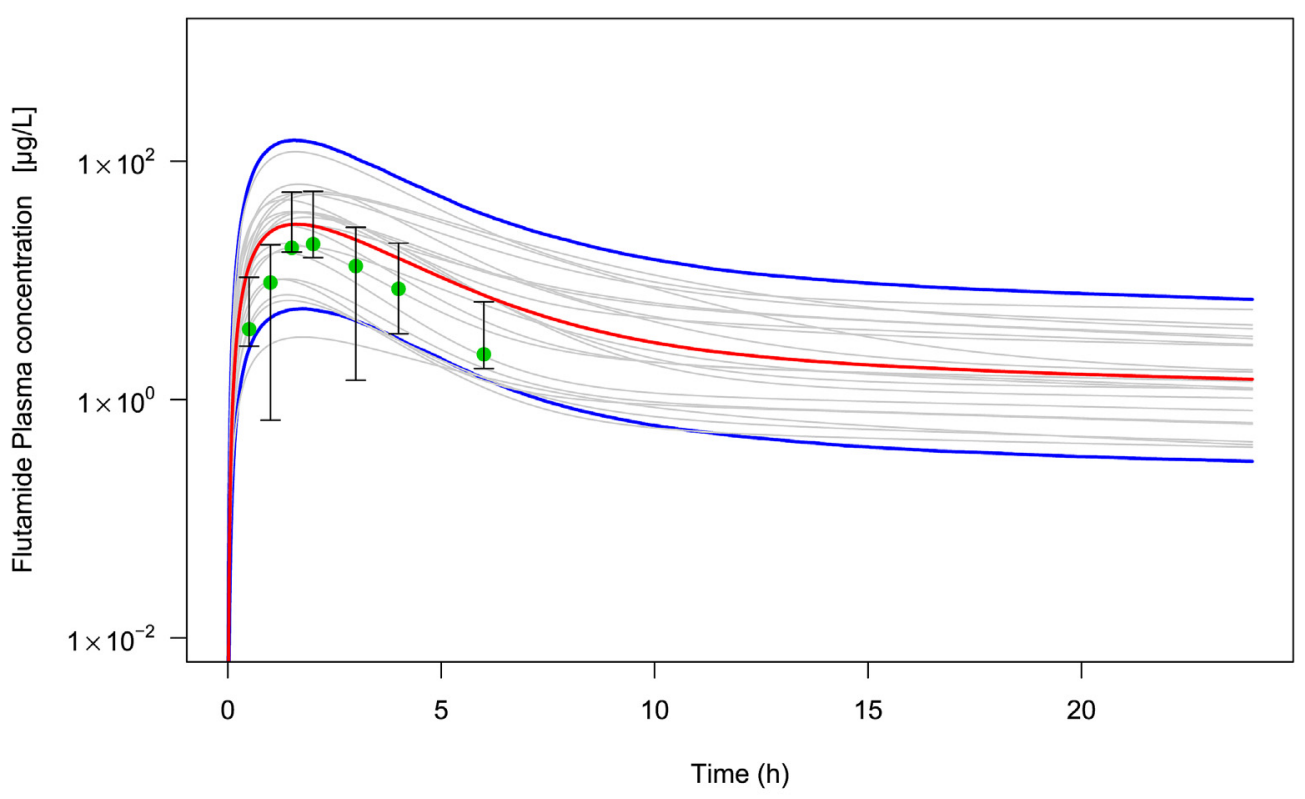

(B)

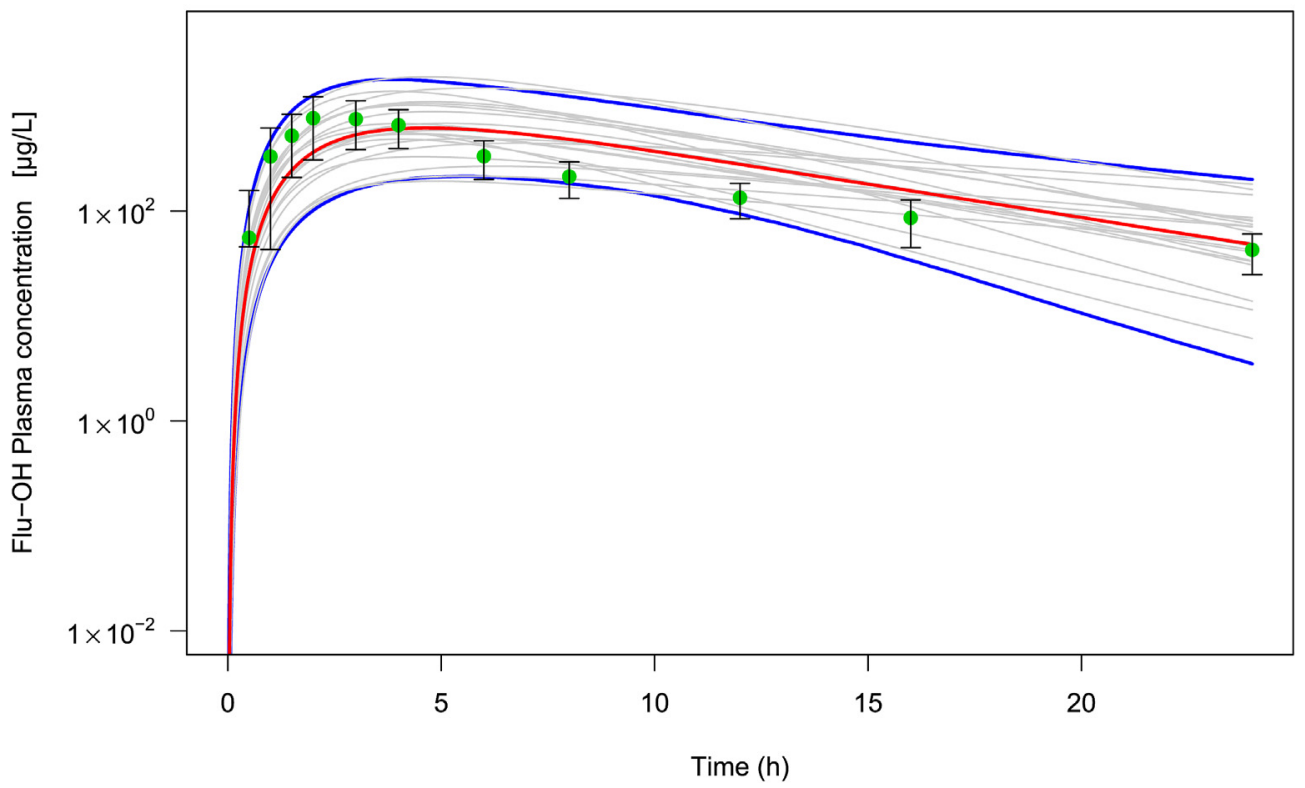

Fig. 5. PBPK model predictions of flutamide (A) and flutamide hydroxide (B) concentrations in human plasma following a $0.25 \mathrm{~g}$ oral dose of flutamide. Red lines: median predictions; blue lines: 2.5 and 97.5 percentiles; gray lines: 20 random simulations from the ensemble of 15,000 iterations. The green dots and black lines indicate the mean \pm sd concentrations reported in Radwanski et al. (1989). (For interpretation of the references to colour in this figure legend, the reader is referred to the Web version of this article.)

multiple iterations with various values for each uncertain parameter in parallel. This led to uncertainties in the predicted dynamic behavior of flutamide concentrations in the various tissues.

When comparing to dynamic distribution of flutamide over seven rat tissues, the model performed fairly: the median values predicted by the model were less than a factor of 10 away from the average experimental value, for most tissues. In other words, the robustness of the developed PBPK model for predicting flutamide levels in different compartments was substantial. Although the model pointed out high uncertainties in the predictions for some compartments (Fig. 3), the observed concentrations were well captured by the predicted intervals (within uncertainty range).

The uncertainty in the rat model predictions was about five times larger than the experimental uncertainty, when evaluated at the 2.5; 97.5 percentile. Surprisingly, predictions for the human plasma levels, although requiring more uncertain steps in model formulation was actually better: the median model values were mostly less than a factor of 4 away from the average experimental value, being the model uncertainty equivalent with the experimental uncertainty. This suggests that further average model refinement makes no sense, because of limitations in the experimental values.

The limitations in the apparent accuracy of the experimental values 
(A)

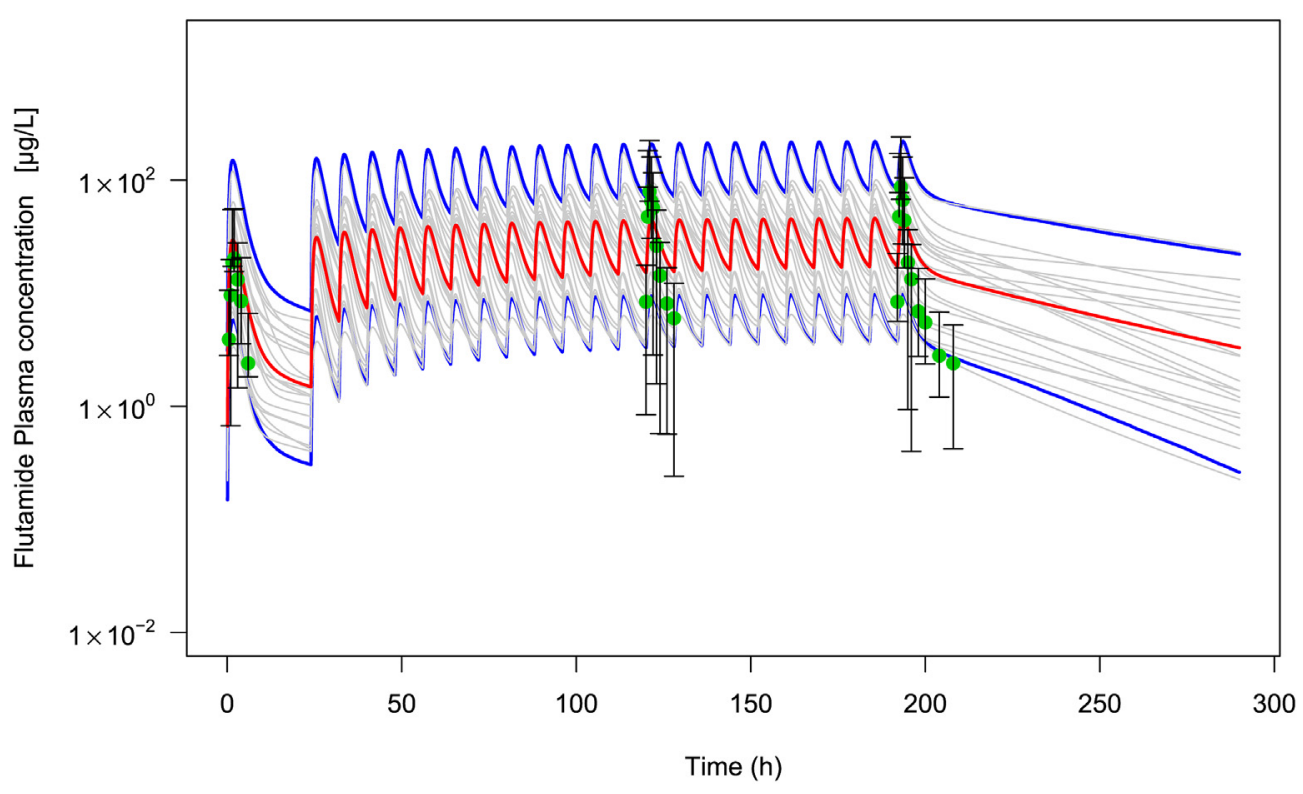

(B)

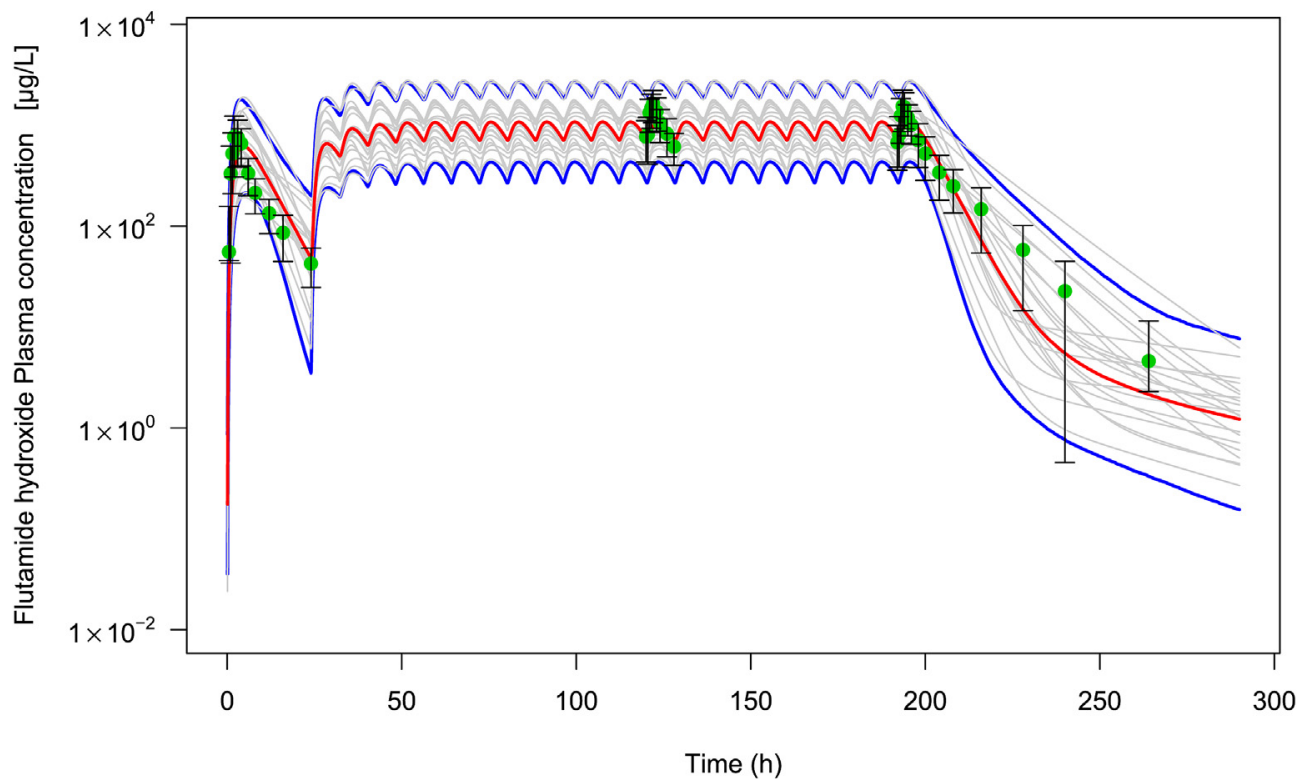

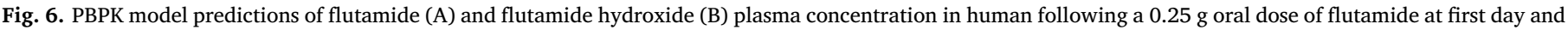

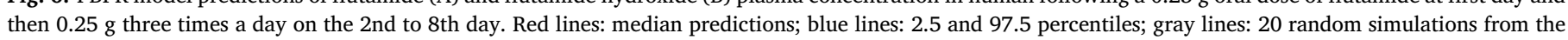

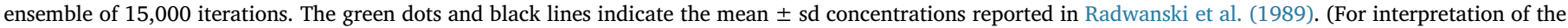
references to colour in this figure legend, the reader is referred to the Web version of this article.)

could be for either of two reasons: The experimental variability may be due to experimental error, or due to biological variation between individuals. Inspecting the original experimental publications, we conclude that the latter explanation is the more likely one. This implies that rather than looking into improvement of the model or for improvement of the experimental methodology, one should begin to make the models in an individualized way.

The extrapolation of the model to predicting flutamide kinetics in humans with two scenarios of dosing (single and multiple) (Figs. 5 and 6) were also in good agreement with the observed data. Moreover, the prediction of flutamide hydroxide and its agreement with observed data (Figs. 5B and 6B), confirmed that the metabolic kinetics for the production of metabolite in liver (flutamide hydroxide) and its distribution to the plasma was well captured. In the model, flutamide hydroxide was confined to liver and plasma, not distributed over all the given compartments owing to the fact of not having data on its biodistributions. In the worst case scenarios, it would be possible to distribute the flutamide hydroxide presuming its partition coefficient similar with its parent compound or by prediction of its partition coefficients using in-silico approach.

PBPK modeling have been used in inter-species, dose, duration and specific population extrapolations for the risk assessment (Andersen, 1995; Andersen and Dennison, 2001; Evans et al., 2008; Thiel et al., 2015). In this work, along with standard cross-species scaling approach 
(A)

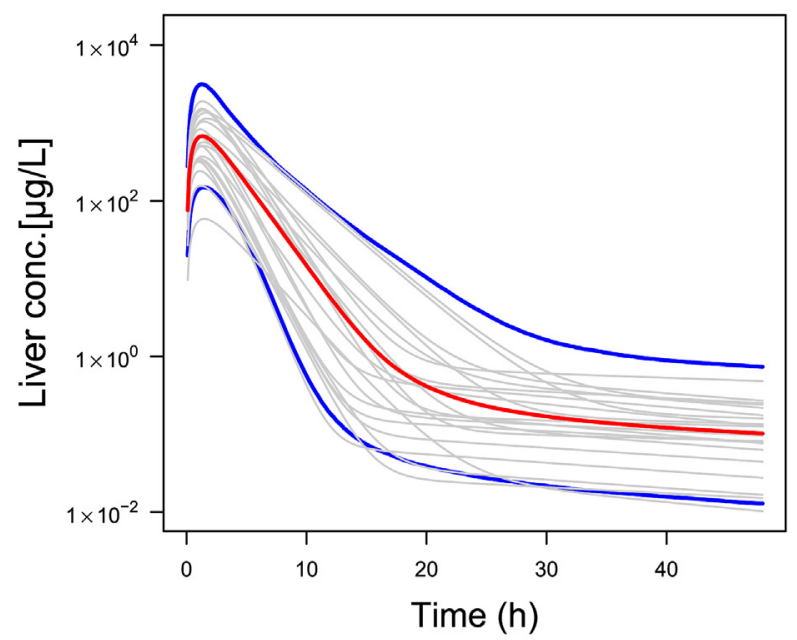

(C)

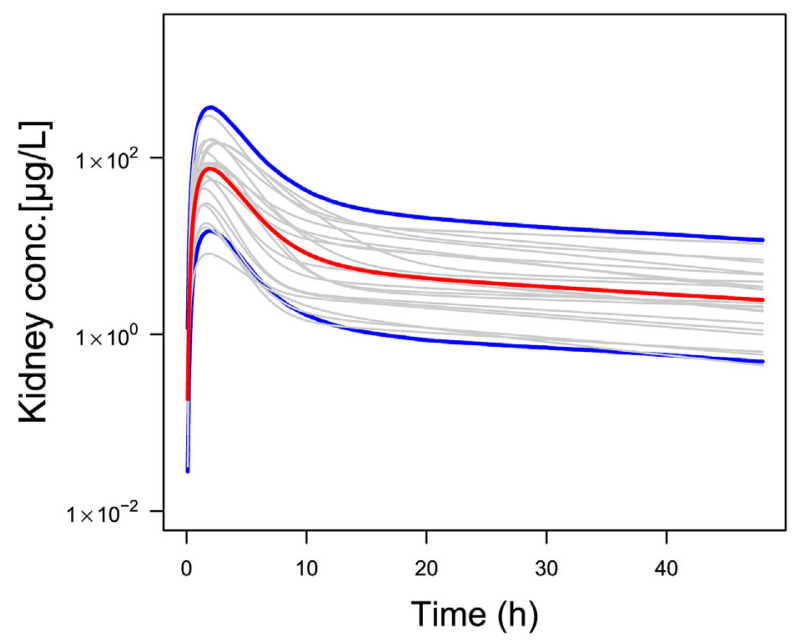

(E)

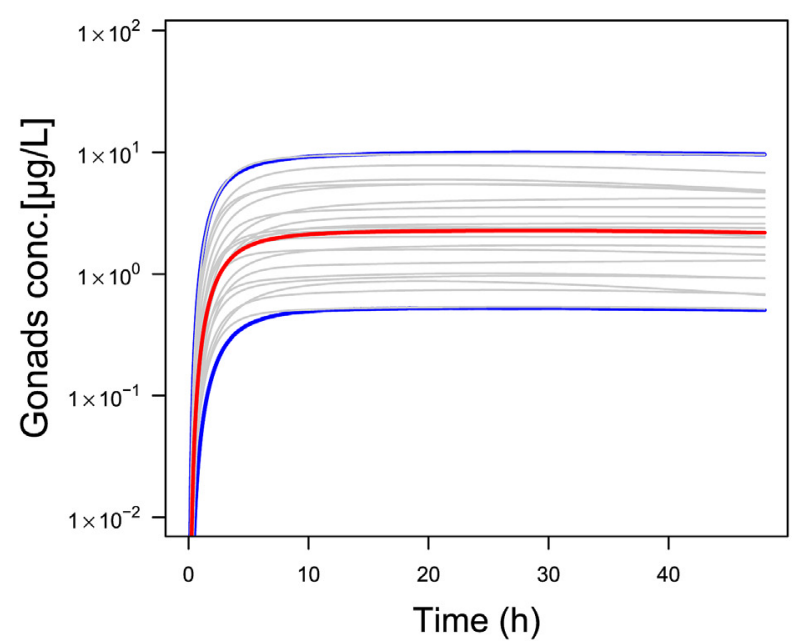

(B)

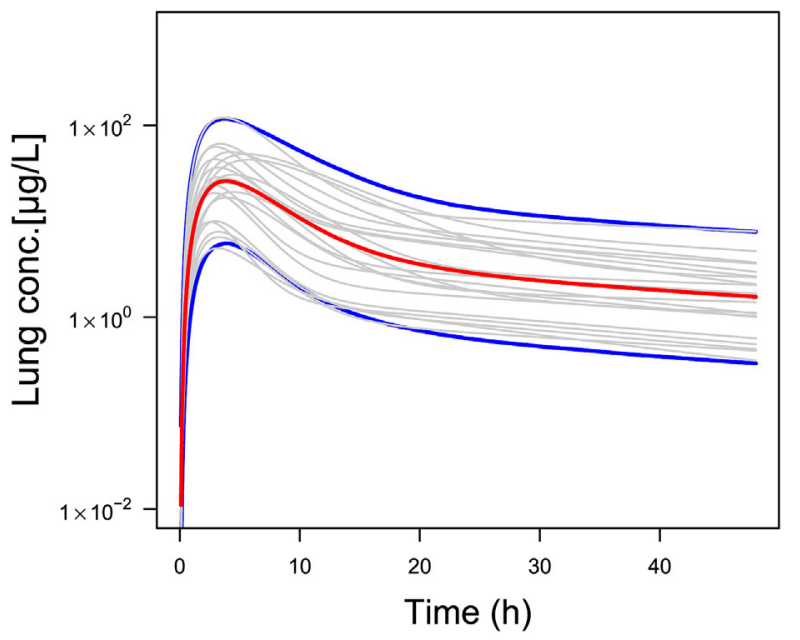

(D)

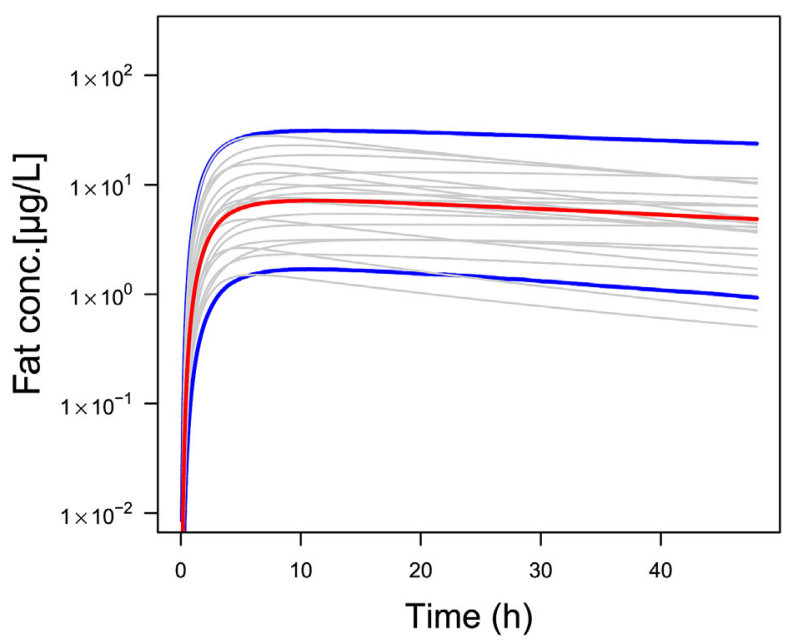

(F)

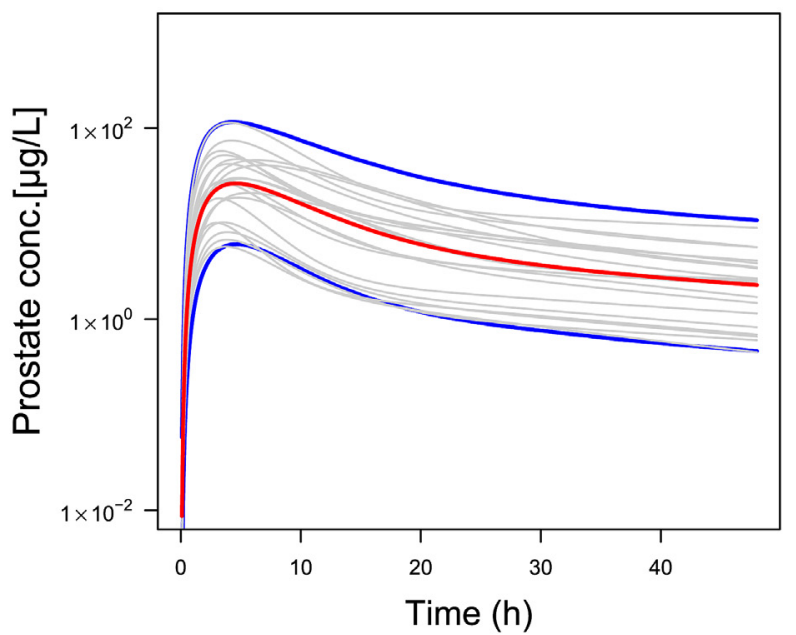

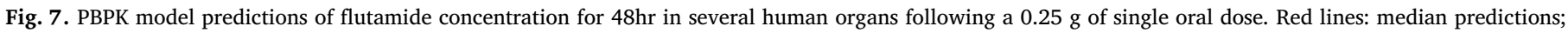

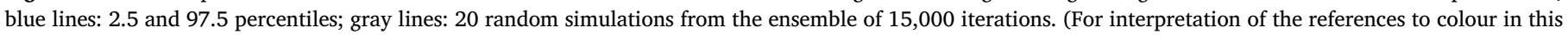
figure legend, the reader is referred to the Web version of this article.) 
(A)

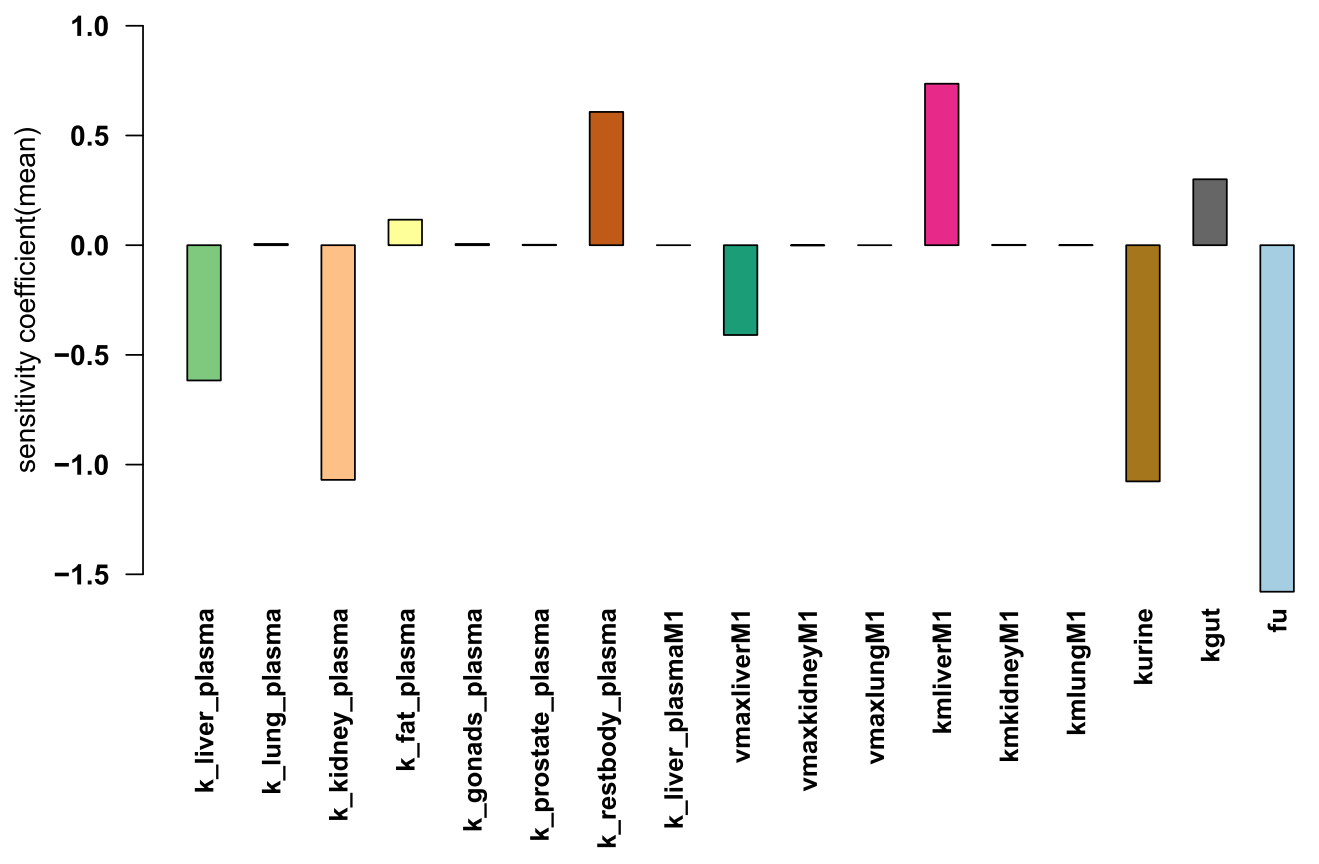

(B)
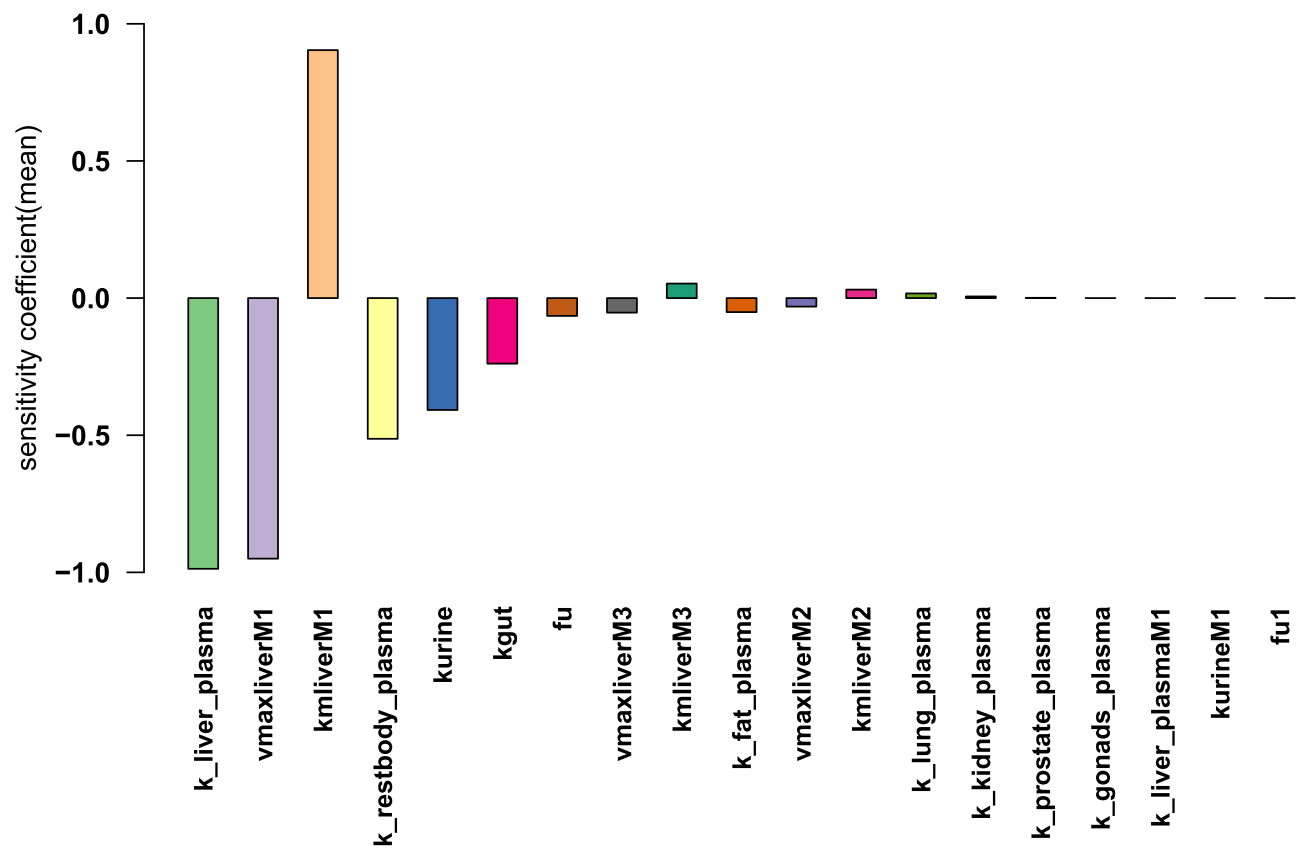

Fig. 8. Normalized sensitivity coefficients for the dependence of plasma flutamide concentration $24 \mathrm{~h}$ after dosing on partition coefficient, Vmax's and KM's, as obtained from simulated time course data of flutamide for $24 \mathrm{hr}$. (A), represents sensitivity coefficients for rat PBPK and (B), represents sensitivity coefficients for human PBPK.

we have harmonized the species specific metabolic parameters input for developing the PBPK model. This was done by integrating in-vitro metabolic kinetics based on IVIVE. The predictions of flutamide and its metabolite flutamide hydroxide kinetics in human plasma for different dose scenarios suggested that the dose dependency of flutamide kinetics was modelled correctly. This might enhance the model's applicability optimization of doses regimens based on not only the parent compound (usual approach) but also its main metabolite flutamide hydroxide, presumably responsible for pharmacological effects. The current model could be useful for extrapolating low dose scenarios that are relevant for environmental exposure of flutamide as a result of pharmaceutical residuals as well as for verifying low dose animal testing endocrine effects.

However additional research is required to better characterize the flutamide kinetics: the dose dependency that we implemented in the model is uncertain as flutamide is metabolized by two different enzymes namely carboxylesterase and arylacetamide deacetylase depending on its concentration (Kobayashi et al., 2012a, 2012b; 
Watanabe et al., 2009). It should also be useful to measure the kinetics of flutamide simultaneously in plasma and urine for the humans, as this should give an additional mode of model validation. Although in this study we have considered the metabolism of flutamide into three different metabolites (assuming hepatic clearance of flutamide), reported studies shows that flutamide can produce even more metabolites in humans, which could lead to a decrease in its own concentration. This would allow for the confirmation of the total observed clearance of flutamide (hepatic and renal) being faster experimentally than in the present model. It also could allow the prediction of other important metabolites as a function of flutamide exposure in the PBPK model and reduce the uncertainties in parameters particularly associated with metabolism and elimination to which the predicted flutamide concentration is sensitive (Fig. 8 and Table 2). Additionally, capturing metabolic variation of flutamide due to variation in enzyme level at target metabolizing tissue (liver), correlating with genetic predisposition, and accounting for changes in CYP activity, could enhance our understanding at the level of a personalized PBPK model for flutamide (Bordbar et al., 2015).

The results of this study are promising for application of PBPK modeling in risk assessments of flutamide in human populations in the context of target tissue concentration. To date, no tool has been developed to predict in humans the chemical kinetics in plasma and more importantly tissues concentration along with time. Several future uses of the PBPK model of flutamide could be considered. Here the model could serve to relate the levels to which humans are exposed to the levels attained in various target organs, suspected to be involved in toxicity. By in vitro tissue-specific cell line experiments one could then determine whether those levels should be expected to be toxic or tumorigenic for those tissues. In other words, the current model could be used in a reverse dosimetry context to interpret the available in vitro biomonitoring data so as to estimate the degree to which the population is currently being exposed, an alternative solution to validate the estimated PDE for flutamide for the pharmaceutical companies.

An important issue for EDCs is their idiosyncrasies, i.e. the phenomenon that even if non-toxic for most of the human population, a fraction of the population may suffer from exposure. One of the origins of this idiosyncrasy may reside in inter-individual differences based on genomic, nutritional or behavioral differences. Such idiosyncrasies are often thought to occur in the PD, i.e. in the effect the EDC has on the body. We suspect that idiosyncrasies may also arise in the PBPK, by some individuals having strongly altered parameters in PD, such as modelled by our model. In future work we shall account for mechanism in our model (or in extended versions thereof) that are affected by known single nucleotide polymorphisms (SNPs) in the human population. These could reside in drug metabolism, or in drug pumping alterations.

Physiologically specific in nature, the current PBPK model for flutamide could also be adapted to the context of a large human population by considering their metabolic and genetic diversity. This could add explanations of otherwise unexpected sensitivities of small fractions of the population to flutamide and corresponding idiosyncrasies.

\section{Acknowledgement}

Preparation of this manuscript was supported in part by the European Union projects HEALS (Health and Environment-wide Associations via Large population Surveys; FP7 Programme under grant agreement no. 603946, EuroMix (European Test and Risk Assessment Strategies for Mixtures); Horizon 2020 Framework Programme under grant agreement no. 633172) Raju Prasad Sharma has received a doctoral fellowship from Universitat Rovira i Virgili under the MartíFranquès Research Grants Programme. V. Kumar has received funds from Health Department of Catalonia Government through "Pla Estratègic de Recerca i Innovació en salut" (PERIS 2016-2020). This work was further supported various systems biology grants to HVW, including Synpol: EU-FP7 (KBBE.2012.3.4-02 \#311815), Corbel: EUH2020 (NFRADEV-4-2014-2015 \#654248), Epipredict: EU-H2020 MSCA-ITN-2014-ETN: Marie Skłodowska-Curie Innovative Training Networks (ITN-ETN) \#642691, BBSRC China: BB/J020060/1.

\section{Appendix A. Supplementary data}

Supplementary data to this article can be found online at https:// doi.org/10.1016/j.envres.2019.108948.

\section{References}

Andersen, M.E., 1995. Development of physiologically based pharmacokinetic and physiologically based pharmacodymamic models for applications in toxicology and risk assessment. Toxicol. Lett. 79, 35-44. https://doi.org/10.1016/0378-4274(95) 03355-O.

Andersen, M.E., Dennison, J.E., 2001. Mode of action and tissue dosimetry in current and future risk assessments. Sci. Total Environ. 274, 3-14. https://doi.org/10.1016/ S0048-9697(01)00744-6.

Asakawa, N., Koyama, M., Hashimoto, Y., Yamashita, K., 1995a. Studies on the metabolic fate of flutamide. (1): plasma concentration after single administration and protein binding in rats. Drug Metab. Pharmacokinet. 10, 447-453. https://doi.org/10.2133/ dmpk.10.447.

Asakawa, N., Koyama, M., Hashimoto, Y., Yamashita, K., Esumi, Y., Takaichi, M., et al., 1995b. Studies on the metabolic fate of flutamide. (2): absorption, distribution and excretion after single oral administration in rats. Drug Metab. Pharmacokinet. 10, 454-463. https://doi.org/10.2133/dmpk.10.454.

Blumberg, B., Iguchi, T., Odermatt, A., 2011. Endocrine disrupting chemicals. J. Steroid Biochem. Mol. Biol. 127, 1-3. https://doi.org/10.1016/j.jsbmb.2011.07.012.

Bois, F.Y., Maszle, D.R., 1997. MCSim : a Monte Carlo simulation program. J. Stat. Softw. 2. https://doi.org/10.18637/jss.v002.i09.

Bordbar, A., McCloskey, D., Zielinski, D.C., Sonnenschein, N., Jamshidi, N., Palsson, B.O., 2015. Personalized whole-cell kinetic models of metabolism for discovery in genomics and pharmacodynamics. Cell Syst. 1, 283-292. https://doi.org/10.1016/j.cels. 2015.10.003.

Brahm, J., Brahm, M., Segovia, R., Latorre, R., Zapata, R., Poniachik, J., et al., 2011. Acute and fulminant hepatitis induced by flutamide: case series report and review of the literature. Ann. Hepatol. 10, 93-98.

Brogden, R.N., Clissold, S.P., 1989. Flutamide. A preliminary review of its pharmacodynamic and pharmacokinetic properties, and therapeutic efficacy in advanced prostatic cancer. Drugs 38, 185-203.

EMEA, 2014. Guideline on setting health based exposure limits for use in risk identification in the manufacture of different medicinal products in shared facilities. Eur. Med. Agency UK 44, 11.

Evans, M.V., Dowd, S.M., Kenyon, E.M., Hughes, M.F., El-Masri, H.A., 2008. A physiologically based pharmacokinetic model for intravenous and ingested dimethylarsinic acid in mice. Toxicol. Sci. 104, 250-260. https://doi.org/10.1093/toxsci/kfn080.

Gallo, J.M., Lam, F.C., Perrier, D.G., 1987. Area method for the estimation of partition coefficients for physiological pharmacokinetic models. J. Pharmacokinet. Biopharm. 15, 271-280. https://doi.org/10.1007/BF01066322.

Hayes, E.P., Jolly, R.A., Faria, E.C., Barle, E.L., Bercu, J.P., Molnar, L.R., et al., 2016. A harmonization effort for acceptable daily exposure application to pharmaceutical manufacturing - operational considerations. Regul. Toxicol. Pharmacol. 79, S39-S47. https://doi.org/10.1016/j.yrtph.2016.06.001.

Howgate, E.M., Rowland Yeo, K., Proctor, N.J., Tucker, G.T., Rostami-Hodjegan, A., 2006a. Prediction of in vivo drug clearance from in vitro data. I: impact of interindividual variability. Xenobiotica 36, 473-497. https://doi.org/10.1080/ 00498250600683197.

Howgate, E.M., Rowland Yeo, K., Proctor, N.J., Tucker, G.T., Rostami-Hodjegan, A., 2006b. Prediction of in vivo drug clearance from in vitro data. I: impact of interindividual variability. Xenobiotica 36, 473-497. https://doi.org/10.1080/ 00498250600683197.

Inaba, T., 1992. Quantitative measurements of prostatic blood flow and blood volume by positron emission tomography. J. Urol. 148, 1457-1460. https://doi.org/10.1016/ S0022-5347(17)36939-2.

Jones, H., Chen, Y., Gibson, C., Heimbach, T., Parrott, N., Peters, S., et al., 2015. Physiologically based pharmacokinetic modeling in drug discovery and development: a pharmaceutical industry perspective. Clin. Pharmacol. Ther. 97, 247-262. https:// doi.org/10.1002/cpt.37.

Katchen, B., Buxbaum, S., 1975. Disposition of a new, nonsteroid, antiandrogen, alpha,alpha, alpha-trifluoro-2-methyl-4'-nitro-m-propionotoluidide (Flutamide), in men following a single oral $200 \mathrm{mg}$ dose. J. Clin. Endocrinol. Metab. 41, 373-379. https:// doi.org/10.1210/jcem-41-2-373.

Kobayashi, Y., Fukami, T., Shimizu, M., Nakajima, M., Tsuyoshi, Y., 2012a. Short communication contributions of arylacetamide deacetylase and carboxylesterase 2 to flutamide hydrolysis in human liver. Drug Metab. Dispos. 40, 1080-1084.

Kobayashi, Y., Fukami, T., Nakajima, A., Watanabe, A., Nakajima, M., Yokoi, T., 2012b. Species differences in tissue distribution and enzyme activities of arylacetamide deacetylase in human, rat, and mouse. Drug Metab. Dispos. 40, 671-679. https://doi. org /10.1124/dmd.111.043067.

Lin, Z., Vahl, C.I., Riviere, J.E., 2016. Human food safety implications of variation in food animal drug metabolism. Sci. Rep. 6, 27907. https://doi.org/10.1038/srep27907. 
Miyata, K., Yabushita, S., Sukata, T., Sano, M., Yoshino, H., Nakanishi, T., et al., 2002. Effects of perinatal exposure to flutamide on sex hormones and androgen-dependent organs in F1 male rats. J. Toxicol. Sci. 27, 19-33. https://doi.org/10.2131/jts.27.19.

Radwanski, E., Perentesis, G., Symchowicz, S., Zampaglione, N., 1989. Single and multiple dose pharmacokinetic evaluation of flutamide in normal geriatric volunteers. J. Clin. Pharmacol. 29, 554-558. https://doi.org/10.1002/j.1552-4604.1989. tb03381.x.

Sharma, R.P., Schuhmacher, M., Kumar, V., 2017a. Developing Integrated PBPK/PD Coupled mechanistic pathway model (miRNA-BDNF): an approach towards System toxicology. Toxicol. Lett. 280, 79-91. https://doi.org/10.1016/j.toxlet.2017.08.003.

Sharma, R.P., Schuhmacher, M., Kumar, V., 2018a. Development of a human physiologically based pharmacokinetic ( PBPK ) model for phthalate ( DEHP) and its metabolites : a bottom up modeling approach. Toxicol. Lett. 1-11. https://doi.org/10. 1016/j.toxlet.2018.06.1217.

Sharma, R.P., Schuhmacher, M., Kumar, V., 2017b. Review on crosstalk and common mechanisms of endocrine disruptors: scaffolding to improve PBPK/PD model of EDC mixture. Environ. Int. 99, 1-14. https://doi.org/10.1016/j.envint.2016.09.016.

Sharma, R.P., Schuhmacher, M., Kumar, V., 2018b. The development of a pregnancy PBPK Model for Bisphenol A and its evaluation with the available biomonitoring data. Sci. Total Environ. 624, 55-68. https://doi.org/10.1016/j.scitotenv.2017.12. 023.

Shet, M.S., McPhaul, M., Fisher, C.W., Stallings, N.R., Estabrook, R.W., 1997. Metabolism of the antiandrogenic drug (Flutamide) by human CYP1A2. Drug Metab. Dispos. 25, 1298-1303.

Shimizu, S., Shimizu, T., Tsounapi, P., Higashi, Y., Martin, D.T., Nakamura, K., et al., 2015. Effect of silodosin, an alpha1A-adrenoceptor antagonist, on ventral prostatic hyperplasia in the spontaneously hypertensive rat. PLoS One 10,1-13. https://doi. org/10.1371/journal.pone.0133798.

Shin, J.H., Kim, H.S., Moon, H.J., Kang, I.H., Kim, T.S., Seok, J.H., et al., 2002. Effects of flutamide on puberty in male rats: an evaluation of the protocol for the assessment of pubertal development and thyroid function. J. Toxicol. Environ. Health Part A 65, 433-445. https://doi.org/10.1080/15287390252808091.

Sjo, E., Lennerna, H., Andersson, T.B., Gråsjo, J., Bredberg, U., 2009. Estimates of intrinsic clearance ( $\mathrm{CL}$ int ), maximum velocity of the metabolic reaction ( $\mathrm{V}$ max ), and Michaelis constant ( $\mathrm{K} \mathrm{m}$ ): accuracy and robustness evaluated through experimental data and Monte Carlo simulations ABSTRACT. Pharmacology 37, 47-58. https://doi. org/10.1124/dmd.108.021477.kinetics.

Sjögren, E., Tammela, T.L., Lennernäs, B., Taari, K., Isotalo, T., Malmsten, L.-Å., et al., 2014a. Pharmacokinetics of an injectable modified-release 2-hydroxyflutamide formulation in the human prostate gland using a semiphysiologically based biopharmaceutical model. Mol. Pharm. 11, 3097-3111. https://doi.org/10.1021/ mp5002813.

Sjögren, E., Tammela, T.L., Lennernäs, B., Taari, K., Isotalo, T., Malmsten, L.Å., et al., 2014b. Pharmacokinetics of an injectable modified-release 2-hydroxyflutamide formulation in the human prostate gland using a semiphysiologically based biopharmaceutical model. Mol. Pharm. 11, 3097-3111. https://doi.org/10.1021/ mp5002813.

Soetaert, K., Petzoldt, T., 2010. Inverse modelling, sensitivity and Monte Carlo analysis in R using package FME. J. Stat. Softw. 33, 2-4. https://doi.org/10.18637/jss.v033.i03.

Tavakkoli, H., Adilipour, H., Tavakkoli, M., Adibi, A., Merat, S., 2011. Flutamide-induced Hepatotoxicity : a case report flutamide-induced Hepatotoxicity : a case report. Govaresh 16, 204-208.

Thiel, C., Schneckener, S., Krauss, M., Ghallab, A., Hofmann, U., Kanacher, T., et al., 2015. A systematic evaluation of the use of physiologically based pharmacokinetic modeling for cross-species extrapolation. J. Pharm. Sci. 104, 191-206. https://doi. org/10.1002/jps.24214.

Toyoda, K., Shibutani, M., Tamura, T., Koujitani, T., Uneyama, C., Hirose, M., 2000a. Repeated dose (28 days) oral toxicity study of flutamide in rats, based on the draft protocol for the 'Enhanced OECD Test Guideline 407' for screening for endocrinedisrupting chemicals. Arch. Toxicol. 74, 127-132. https://doi.org/10.1007/ s002040050664.

Toyoda, K., Shibutani, M., Tamura, T., Koujitani, T., Uneyama, C., Hirose, M., 2000b. Repeated dose (28 days) oral toxicity study of flutamide in rats, based on the draft protocol for the 'Enhanced OECD Test Guideline 407' for screening for endocrinedisrupting chemicals. Arch. Toxicol. 74, 127-132. https://doi.org/10.1007/ s002040050664.

Watanabe, A., Fukami, T., Nakajima, M., Takamiya, M., Aoki, Y., Yokoi, T., 2009. Human arylacetamide deacetylase is a principal enzyme in flutamide hydrolysis. Drug Metab. Dispos. 37, 1513-1520. https://doi.org/10.1124/dmd.109.026567.

Wen, B., Coe, K.J., Rademacher, P., Fitch, W.L., Monshouwer, M., Nelson, S.D., 2008. Comparison of in vitro bioactivation of flutamide and its cyano analogue: evidence for reductive activation by human NADPH:cytochrome P450 reductase. Chem. Res. Toxicol. 21, 2393-2406. https://doi.org/10.1021/tx800281h.

Xu, C.J., Li, D., 1998. Pharmacokinetics of flutamide and its metabolite 2-hydroxyflutamide in normal and hepatic injury rats. Zhongguo Yaoli Xuebao 19, 39-43.

Yoon, M., Efremenko, A., Blaauboer, B.J., Clewell, H.J., 2014. Evaluation of simple in vitro to in vivo extrapolation approaches for environmental compounds. Toxicol. In Vitro 28, 164-170. https://doi.org/10.1016/j.tiv.2013.10.023.

Zacharia, L.C., 2017. Permitted daily exposure of the androgen receptor antagonist flutamide. Toxicol. Sci. 159, 279-289. https://doi.org/10.1093/toxsci/kfx135.

Zhuang, X., Lu, C., 2016. PBPK modeling and simulation in drug research and development. Acta Pharm. Sin. B 6, 430-440. https://doi.org/10.1016/j.apsb.2016.04.004. 